\title{
Levels and actions of progesterone and its metabolites in the nervous system during physiological and pathological conditions
}

\author{
Roberto Cosimo Melcangi ${ }^{\mathrm{a}, *}$, Silvia Giatti ${ }^{\mathrm{a}}$, Donato Calabrese ${ }^{\mathrm{a}}$, Marzia Pesaresi ${ }^{\mathrm{b}}$, \\ Gaia Cermenati ${ }^{a}$, Nico Mitro $^{a}$, Barbara Viviani ${ }^{a}$, Luis Miguel Garcia-Segura ${ }^{c}$, \\ Donatella Caruso $^{\mathrm{a}}$ \\ ${ }^{a}$ Dept. of Pharmacological and Biomolecular Sciences, Section of Biomedicine and Endocrinology, Center of Excellence on Neurodegenerative Diseases, \\ Università degli Studi di Milano, Via Balzaretti 9, 20133 Milano, Italy \\ ${ }^{\mathrm{b}}$ Rotman Research Institute, Toronto, Ontario, Canada \\ ${ }^{\mathrm{c}}$ Instituto Cajal, CSIC, E-28002 Madrid, Spain
}

\section{A R T I C L E IN F O}

\section{Article history:}

Received 18 May 2013

Received in revised form 17 July 2013

Accepted 31 July 2013

Available online 16 August 2013

\section{Keywords:}

Neuroactive steroids

Metabolism

Allopregnanolone

Neurodegeneration

Gonadectomy

Neuroprotection

\begin{abstract}
A B S T R A C T
Progesterone is synthesized and actively metabolized in the central and peripheral nervous system, into neuroactive steroid metabolites, such as dihydroprogesterone, allopregnanolone and isopregnanolone. Progesterone and/or its metabolites exert a variety of effects acting as physiological regulators of neuronal and glial development and plasticity, controlling reproduction, neuroendocrine events, mood and affection. In addition, these neuroactive steroids maintain neural homeostasis and exert neuroprotective actions. In agreement, metabolic pathways of progesterone are affected by modifications in the level of gonadal hormones and by pathology or injury with a regional specificity and in a sex-dimorphic way. Therefore, observations here summarized may provide a background to design sex-specific therapies based on progesterone metabolites. On this point of view, considering that one of the major limits of a therapy based on neuroactive steroids could be modifications in their plasma levels and their consequent peripheral effects, pharmacological treatments aimed to increase their levels in the nervous system could provide an interesting therapeutic option.
\end{abstract}

(c) 2013 Elsevier Ltd. All rights reserved.

\section{Contents}

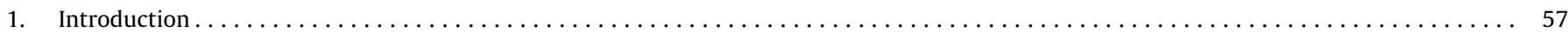

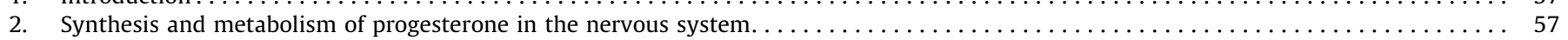

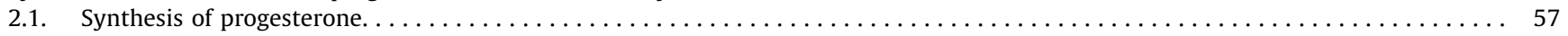

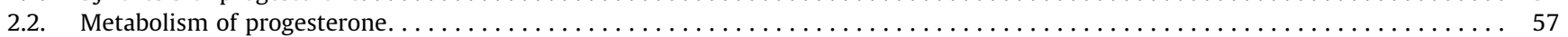

2.3. Modulation of the synthesis and metabolism of progesterone in the nervous system by steroid hormones $\ldots \ldots \ldots \ldots \ldots \ldots \ldots \ldots$

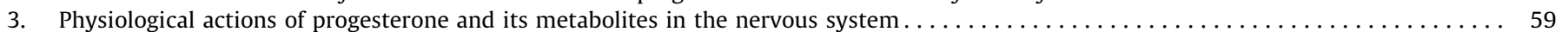

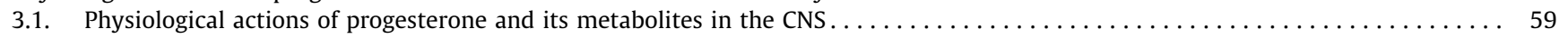

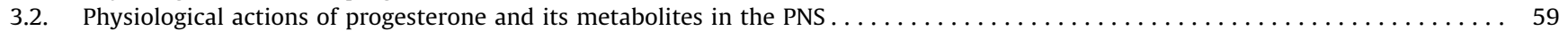

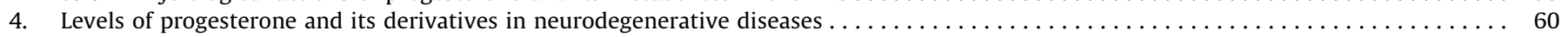

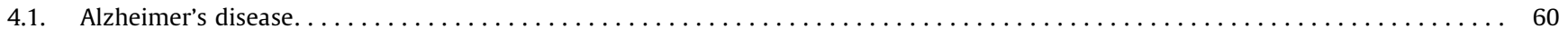

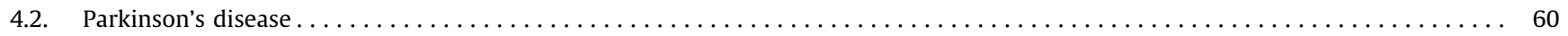

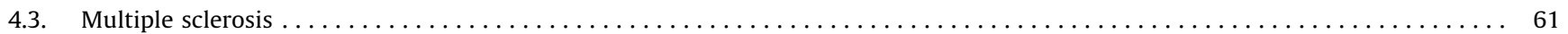

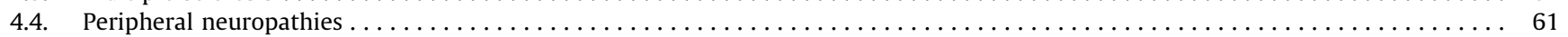

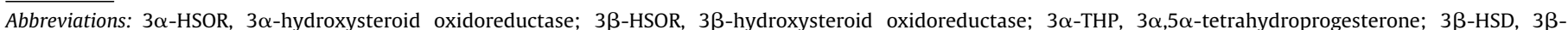

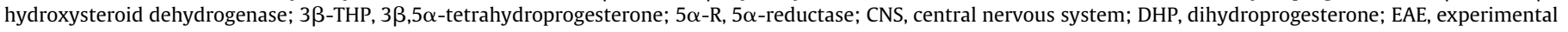

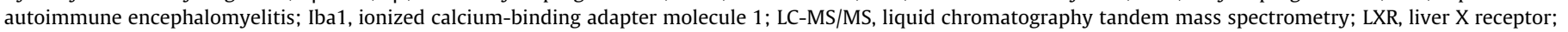

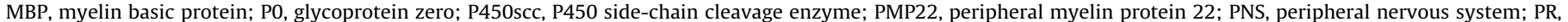

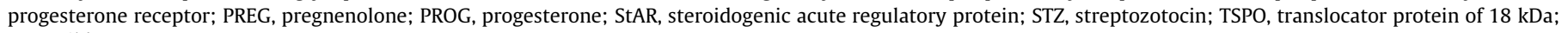
WT, wild type.
\end{abstract}

* Corresponding author. Tel.: +39 02 50318238; fax: +39 0250318204 .

E-mail address: roberto.melcangi@unimi.it (R.C. Melcangi). 


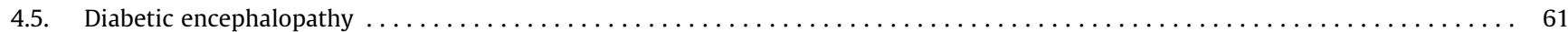

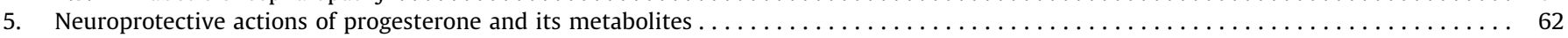

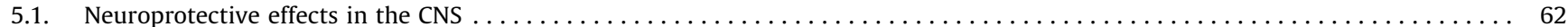

5.1.1. Mechanisms of neuroprotection by PROG and its metabolites in the CNS $\ldots \ldots \ldots \ldots$

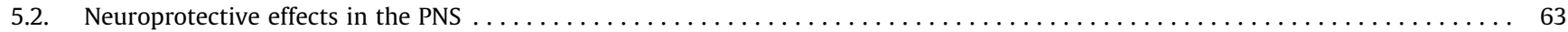

6. Pharmacological approaches to increase the levels of progesterone metabolites during neurodegeneration . . . . . . . . . . . . 63

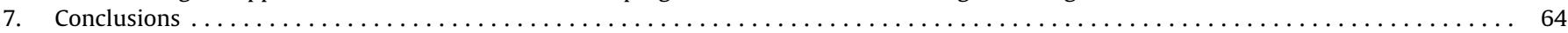

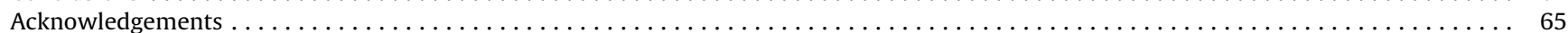

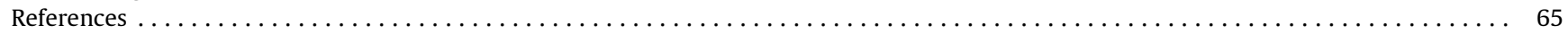

\section{Introduction}

Neuroactive steroids are steroid molecules acting in the nervous system. These molecules are synthesized by neurons and glial cells (i.e., neurosteroids) and in peripheral glands, such as the testis, the ovary and the adrenal glands (i.e., steroid hormones) (Melcangi et al., 2008). The present review will focus on progesterone (PROG) and its metabolites, dihydroprogesterone (DHP), $3 \alpha, 5 \alpha$-tetrahydroprogesterone ( $3 \alpha-\mathrm{THP})$, also known as allopregnanolone, and $3 \beta, 5 \alpha$-tetrahydroprogesterone ( $3 \beta$-THP), also known as isopregnanolone. Indeed, these neuroactive steroids are synthesized and metabolized in the nervous system and recent studies have shown that their levels can be affected by pathology or injury, as demonstrated in experimental models of Alzheimer's disease, Parkinson's disease, multiple sclerosis, peripheral neuropathies and diabetic encephalopathy (Caruso et al., 2008a, 2010a, 2013; Giatti et al., 2010, 2013; Labombarda et al., 2006b; Meffre et al., 2007; Melcangi et al., 2012; Melcangi and Garcia-Segura, 2010; Pesaresi et al., 2010b).

In turn, as demonstrated in experimental models and in clinical studies, PROG and its metabolites exert a variety of effects acting as physiological regulators of nervous function as well as protective agents. Therefore, a potential role of these molecules as components of therapeutic strategies for neurodegenerative and psychiatric disorders has been recently proposed.

\section{Synthesis and metabolism of progesterone in the nervous system}

\subsection{Synthesis of progesterone}

It is now well ascertained that synthesis and metabolism of neuroactive steroids occur in neurons and glial cells (i.e., astrocytes, oligodendrocytes and Schwann cells) of the central (CNS) and peripheral (PNS) nervous system (Garcia-Segura and Melcangi, 2006; Melcangi et al., 2008; Panzica and Melcangi, 2008; Pelletier, 2010). Steroidogenesis is a process highly compartmentalized in a sequence of reactions, which implies as first step the translocation of cholesterol from the cytoplasm to the inner mitochondrial membrane. This is a limiting step hormonally controlled and mediated by the steroidogenic acute regulatory protein (StAR) (Lavaque et al., 2006) and the translocator protein of $18 \mathrm{kDa}$ (TSPO) (Papadopoulos et al., 2006a). In the mitochondria, cholesterol is then converted into pregnenolone (PREG) by the action of P450 side-chain cleavage enzyme (P450scc also known as CYP11A1). PREG is then transformed into progesterone (PROG) by the action of the enzyme $3 \beta$-hydroxysteroid dehydrogenase ( $3 \beta$ HSD) (Melcangi et al., 2008) (Fig. 1).

\subsection{Metabolism of progesterone}

Enzymes involved in the metabolism of PROG are expressed, in CNS and PNS, by neurons, astrocytes, oligodendrocytes and Schwann cells (Pelletier, 2010). PROG is converted into DHP by
( $5 \alpha-\mathrm{R})$. In turn, DHP is further converted into $3 \alpha$-THP or $3 \beta$-THP by $3 \alpha$-hydroxysteroid oxidoreductase ( $3 \alpha$-HSOR) and $3 \beta$-hydroxysteroid oxidoreductase ( $3 \beta-\mathrm{HSOR}$ ), respectively (Melcangi et al., 2008) (Fig. 1).

The metabolism of PROG has a deep impact on the mechanism of action of this neuroactive steroid. Indeed, while DHP, like PROG, is able to interact with the classical steroid receptor, the PROG receptor (Melcangi et al., 2008), $3 \alpha$-THP is a potent ligand of a nonclassical steroid receptor, such as the GABA-A receptor (Belelli and Lambert, 2005; Lambert et al., 2003). In contrast, 3 $\beta$-THP, does not bind directly to the GABA-A receptor (Bitran et al., 1991), but it antagonizes the effect of $3 \alpha-\mathrm{THP}$ on the GABA-A receptor (Wang et al., 2002). Thus, metabolic conversion of PROG into its derivatives might differently and specifically modulate the mechanism of action of the precursor molecule by recruiting CNS specific pathways.

2.3. Modulation of the synthesis and metabolism of progesterone in the nervous system by steroid hormones

The effects that modifications in the peripheral levels of steroid hormones have on the levels of PROG and its metabolites in nerve tissue have been studied in rats. Data so far obtained have

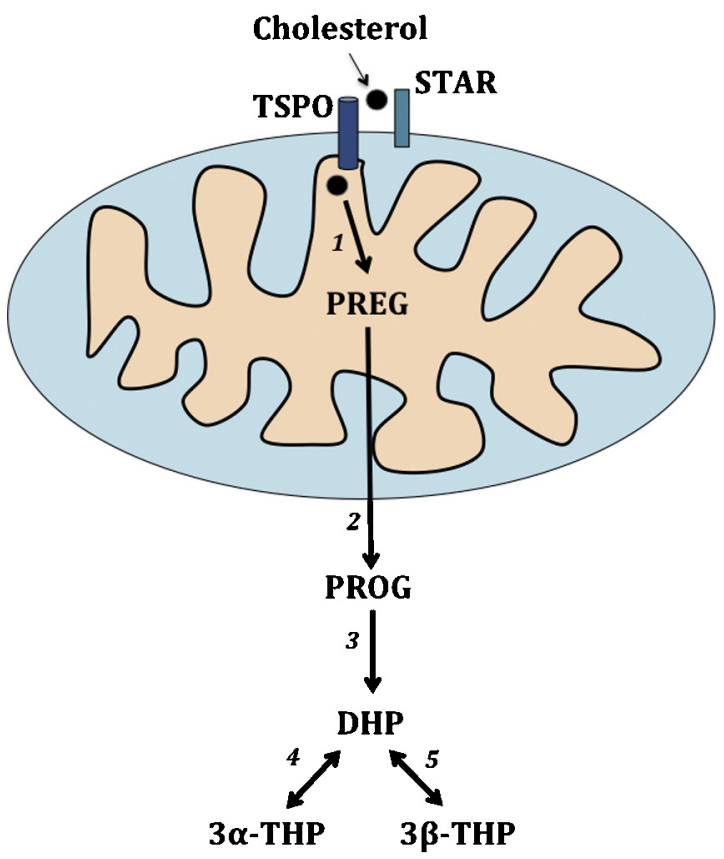

Fig. 1. Formation of progesterone and its metabolism in the nervous system. Details are provided in the text. TSPO: translocator protein of $18 \mathrm{kDa}$; StAR: steroidogenic acute regulatory protein;1: cytochrome P450scc; 2: 3 $\beta$-hydroxysteroid dehydrogenase; 3: $5 \alpha$-reductase; 4: $3 \alpha$-hydroxysteroidoxidoreductase; 5 : $3 \beta$ hydroxysteroidoxidoreductase; PREG: pregnenolone; PROG: progesterone; DHP: dihydroprogesterone; $3 \alpha$-THP: $3 \alpha, 5 \alpha$-tetrahydroprogesterone; $3 \beta$-THP: $3 \beta, 5 \alpha-$ tetrahydroprogesterone. 
demonstrated that after 15 days of orchidectomy, the levels of PREG, the PROG precursor, persisted in the brain (Jo et al., 1989). Further studies with the same experimental protocol have indicated that in the brain of castrated and adrenalectomized male and female rats PROG and its metabolite DHP are still present in measurable amounts (Corpechot et al., 1993). Moreover, after three weeks of gonadectomy and adrenalectomy, significant amounts of PREG and PROG still remained in the spinal cord of male rats (Coirini et al., 2002).

These observations have been confirmed by studies performed on proteins involved in steroidogenesis, such as StAR and 3 $\beta$-HSD. In particular, it has been demonstrated that both in male and female rats, StAR mRNA levels present in the brain were not significantly affected after 3 weeks of gonadectomy and adrenalectomy (Kim et al., 2003). After the same period of gonadectomy and adrenalectomy, $3 \beta$-HSD mRNA and protein levels were not modified in spinal cord of male rats (Coirini et al., 2002).

We have recently analyzed, by liquid chromatography tandem mass spectrometry (LC-MS/MS), the amounts of neuroactive steroids in the sciatic nerve, in three CNS regions (i.e., cerebellum, cerebral cortex and spinal cord) and in plasma of male and female animals. The levels present in gonadally intact animals were compared with those present in short (one week) and long-term (4 months) gonadectomized animals (Caruso et al., 2010b). Data obtained indicate that the absolute concentrations of neuroactive steroids show sex and regional differences in the nervous system of control animals. As already reported by our studies (Pesaresi et al., 2010b), we confirmed that in sciatic nerve, the levels of PREG, PROG and its derivatives are higher in females. In the case of PREG and $3 \beta-T H P$, this sex difference seems to be a peculiarity of the PNS. Moreover, in female animals, the concentration of $3 \beta$-THP in PNS is higher than that in the CNS. Finally, among female CNS areas, the spinal cord and the cerebellum show higher levels of DHP, associated with lower levels of its precursor PROG, in comparison to the cerebral cortex (Caruso et al., 2010b).

Another key point emerging from this study was a different modulation of neuroactive steroid levels by gonadectomy in the PNS compared to the CNS, and within different CNS regions. Concerning other regional differences, in male rats the levels of the precursor of PROG (i.e., PREG) decrease after short-term gonadectomy in the spinal cord, but remain unchanged in the sciatic nerve and the cerebellum (Caruso et al., 2010b).

Uptake from periphery partly determines the levels of neuroactive steroids in the PNS and the CNS. For instance, it is well known that PROG originating in the periphery is taken up by the nervous system in considerable amounts (Billiar et al., 1975). We observed that females have higher levels of PROG in the PNS and CNS than males, which reflect their plasma concentration. However, as also reported in previous studies (Corpechot et al., 1993; Jo et al., 1989; Labombarda et al., 2006b; Robel et al., 1995), we observed that not all the changes in neuroactive steroid levels in the nervous system after gonadectomy are correlated with changes in plasma levels (Caruso et al., 2010b). Indeed, differently from what observed in plasma, detectable amounts of neuroactive steroids are still maintained in nervous system of gonadectomized animals. In addition, we have observed that some neuroactive steroids levels increase in the nervous system after gonadectomy. For instance, at variance to what is observed in the plasma of male animals, in the cerebral cortex short-term gonadectomy increases the levels of DHP, the first derivative of PROG. Long-term gonadectomy also induced an increase of PREG in female cerebellum. These increases in neuroactive steroids do not reflect the changes in plasma, where short- or long-term gonadectomy causes a decrease or result in undetectable levels of these molecules. Therefore, our findings suggest that gonadectomy, by still unidentified mechanisms, affects the rate of local synthesis and/or local metabolism of some specific steroids in the nervous system. Altogether these observations strongly support the idea that peripheral and central regulation of steroids levels might be partly independent (Caruso et al., 2010b).

In some cases, changes in the levels of steroids after gonadectomy within a specific brain region parallel the changes in their precursors in the same brain region. For instance, PROG content is determined by the changes in PREG; in turn $3 \alpha$-THP concentration is dependent on the levels of PROG levels (Caruso et al., 2010b). However, in other cases there is not a direct match between the difference in the levels of the precursor and the metabolite. Therefore, the regional and sex specific modifications in steroid levels in the nervous system after gonadectomy might reflect multiple mechanisms, including differences in local steroidogenesis, changes in retention of steroids and/ or modifications in local steroid metabolism.

Another important finding is that long-term or short-term gonadectomy differently affect levels of neuroactive steroids in the PNS and the CNS. Thus, the amounts of some steroids are reduced by short-term gonadectomy and then recover to control values after long-term gonadectomy. An example of this phenomenon is represented by the changes in the levels of PREG in the spinal cord of male rats after gonadectomy (Caruso et al., 2010b).

In conclusion, as summarized in Fig. 2, gonadectomy influences the metabolism of PROG in nervous system depending on several variables. In particular, data so far obtained indicate that: (1) changes in the levels of PROG, its precursor PREG and its metabolites DHP, $3 \alpha$-THP and $3 \beta$-THP in the nervous system after gonadectomy do not necessarily reflect their changes in plasma levels; (2) longterm gonadectomy induces changes in the levels of these neuroactive steroids in both PNS and CNS that in some cases are different to those induced by short-term gonadectomy; (3) the effect of gonadectomy on the levels of these neuroactive steroids is different between the PNS and the CNS and within different CNS regions and (4) the effects of gonadectomy on the levels of these neuroactive steroids in the nervous system show sex differences. Altogether, these observations indicate that the nervous system adapts its local levels of PREG, PROG and its metabolites in response to changes in gonadal hormones. This response is sex and regional specific and depends on the duration of the peripheral modifications (Caruso et al., 2010b).

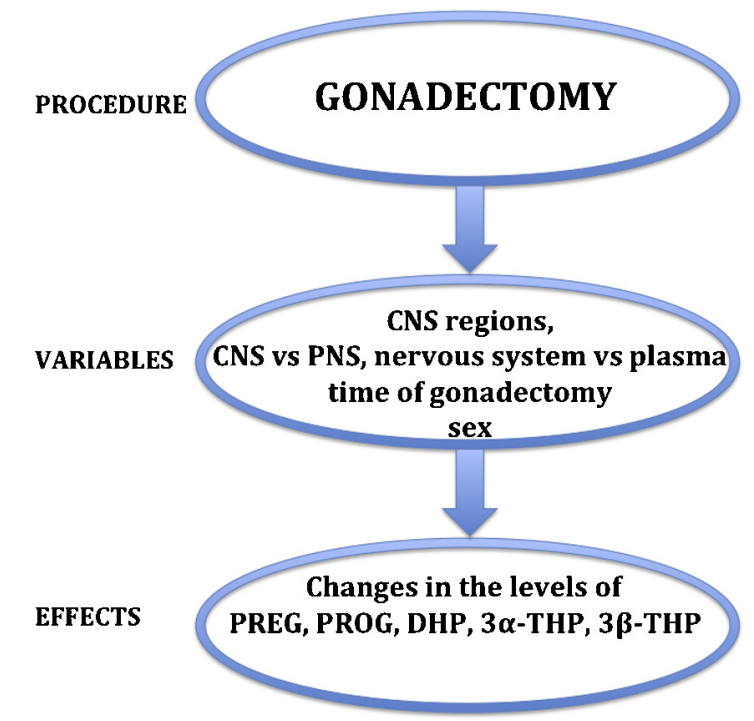

Fig. 2. Variables influencing the effect of gonadectomy on the levels of pregnenolone (PREG), progesterone (PROG) and its metabolites, such as

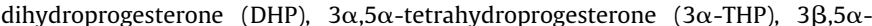
tetrahydroprogesterone ( $3 \beta-\mathrm{THP})$ occurring in plasma and in the central (CNS) and peripheral (PNS) nervous system. Details are provided in the text. 


\section{Physiological actions of progesterone and its metabolites in the nervous system}

\subsection{Physiological actions of progesterone and its metabolites in the CNS}

The best characterized physiological function of PROG is the regulation of reproduction. Acting on the hypothalamus, PROG contributes to regulate the release of gonadotrophins (Banks and Freeman, 1980; Barraclough et al., 1986) and dampens GnRH pulsatility (Skinner et al., 1998). In addition, acting on the ventromedial hypothalamic nucleus, PROG regulates estrous responsiveness (Barfield et al., 1984). The role of PROG in the control of reproduction involves both hormonal and local actions. Thus, changes in PROG levels in plasma during the ovarian cycle as well as changes in the local synthesis of PROG by hypothalamic astrocytes (Micevych and Sinchak, 2008) participate in the control of reproduction.

PROG has also developmental effects in the brain, regulating the development of some neuronal types, such as the Purkinje cells of the cerebellum (Tsutsui et al., 2011). Another important developmental action of PROG is the regulation of the differentiation and proliferation of oligodendrocytes (Ghoumari et al., 2003, 2005; Jung-Testas et al., 1996b). In the adult brain, PROG regulates cytoskeletal proteins and the morphology of neurons and astrocytes (Guerra-Araiza et al., 2007; Reyna-Neyra et al., 2002). Thus, changes in plasma levels of PROG during the estrous cycle contribute to the regulation of astroglial (Garcia-Segura et al., 1994; Luquin et al., 1993) and synaptic plasticity (Foy et al., 2008; Garcia-Segura et al., 1994; McEwen and Woolley, 1994; Murphy and Segal, 2000; Perez et al., 1993; Woolley and McEwen, 1993) in the hypothalamus and the hippocampus. PROG also regulates adult neurogenesis in the subventricular zone and the hippocampus (Giachino et al., 2003; Wang et al., 2008).

The actions of PROG during physiological conditions involve the regulation of the activity of different kinases and phosphatases (Amorim et al., 2010; Frye and Walf, 2008; Guerra-Araiza et al., 2007, 2009; Mani and Oyola, 2012) and the activation of membrane and intracellular progesterone receptors (Brinton et al., 2008; Mani and Oyola, 2012; Meffre et al., 2013). PROG and its metabolite DHP bind to intracellular PROG receptors (Melcangi et al., 2008), which are expressed in the nervous system (Guerra-Araiza et al., 2003). PROG may also act through membrane PROG receptors, which are widely expressed in the brain and the spinal cord (Brinton et al., 2008; Labombarda et al., 2010; Meffre et al., 2013; Thomas and Pang, 2012). In several cases the physiological actions of PROG are mediated by its reduced metabolite 3 $\alpha$-THP (Giachino et al., 2003; Guerra-Araiza et al., 2007,2009 ) and may involve the regulation of the activity of GABA-A receptors (Follesa et al., 2001; Lambert et al., 2003; Majewska et al., 1986; Wang, 2011). Indeed, $3 \alpha$-THP is an important allosteric modulator of GABA-A receptor at different life stages (Biggio et al., 2009; Turkmen et al., 2011) and also regulates GABA and glutamate release (Giuliani et al., 2013). The actions of $3 \alpha$-THP on the activity of GABA-A receptor may contribute to changes in mood and affection (Biggio et al., 2009; Eser et al., 2008; Turkmen et al., 2011; Wirth, 2011). In addition, $3 \alpha$-THP may also regulate neuronal function by acting on membrane PROG receptors (Pang et al., 2013; Thomas and Pang, 2012).

\subsection{Physiological actions of progesterone and its metabolites in the} PNS

Peripheral nerves and Schwann cells are also a physiological target of PROG and its metabolites. Indeed, PROG receptor
(Groyer et al., 2006; Jung-Testas et al., 1996a; Melcangi et al., 2001) as well as GABA-A receptors have been identified in peripheral nerves and Schwann cells (Magnaghi et al., 2004; Melcangi et al., 1999). PROG and its derivatives modulate the expression of myelin proteins of the PNS, such as glycoprotein zero (P0) and the peripheral myelin protein 22 (PMP22). In this regard, the expression of $\mathrm{PO}$ in sciatic nerve of adult male rats, as well as that in rat Schwann cell culture, was increased by the treatment with PROG, DHP or $3 \alpha$-THP, while in case of PMP22, only $3 \alpha-$ THP was effective (Melcangi et al., 2005, 1999). P0 and PMP22 play an important role for the maintenance of the multilamellar structure of PNS myelin (D'Urso et al., 1990). In agreement with the effect exerted on the proteins of peripheral myelin, PROG is also able to stimulate the myelin formation (Chan et al., 1998, 2000).

The mechanism involved in the effects of PROG and its metabolites are different depending on the myelin protein considered. Indeed, observations performed with receptor agonists or antagonists suggest that the expression of $\mathrm{PO}$ is under the control of PROG receptor (PR), while a role for GABA-A receptor, may be hypothesized in case of PMP22 (Melcangi et al., 2005). Activation of PR clearly suggests that the effect of PROG derivatives on P0 expression is due to a classical steroid genomic effect. This concept was supported by the finding that putative progesterone responsive elements are present on P0 gene (Magnaghi et al., 1999) and that a coactivator, such as steroid receptor coactivator-1, participates in the regulation of PO gene expression by DHP (Cavarretta et al., 2004). Since in vivo treatment with mifepristone (i.e., a PR antagonist) specifically decreased the synthesis of P0 at postnatal day 20 (Melcangi et al., 2003b), it has been proposed that PROG derivatives may be necessary for inducing P0 synthesis during the first steps of the myelination process. Differently from what observed on P0, expression of PMP22 seems to be under the control of GABA-A receptor. Indeed, treatment with antagonist (i.e., bicuculline) or agonist (i.e., muscimol) of GABA-A receptor abolished or mimicked, respectively the stimulatory effect exerted by $3 \alpha$-THP on PMP22 (Magnaghi et al., 2001). $3 \alpha$-THP also influences GABA pathways in Schwann cells by increasing the expression of glutamic acid decarboxylase and the consequent stimulation of GABA synthesis (Magnaghi et al., 2010). $3 \alpha$-THP also increases the activity of excitatory amino acid carrier 1 and therefore, glutamate uptake (Perego et al., 2011). Therefore, PROG and its metabolites also regulate myelination program by controlling the expression of its transcription factors. For instance, PROG stimulates the gene expression of Krox-20, Krox-24, Egr-3 and FosB (Guennoun et al., 2001; Mercier et al., 2001). Moreover, the expression of Krox-20 was also stimulated by DHP and $3 \alpha$-THP, while that of another transcription factor, such as Sox-10, was only stimulated by DHP (Magnaghi et al., 2007).

The control exerted by PROG and its metabolites on the expression of P0 and PMP22 is sexually dimorphic. Thus, PROG or DHP treatment induces a stimulatory effect on P0 mRNA levels in cultures of rat Schwann cells derived from male rats, while $3 \alpha$-THP was only effective in Schwann cells derived from females. In addition, PMP22 was stimulated by PROG in cultures from males and by $3 \alpha$-THP in cultures from females (Magnaghi et al., 2006). PROG and its metabolites are also able to affect Schwann cell proliferation. A stimulatory effect of PROG has been detected in vitro (Bartolami et al., 2003; Fex Svenningsen and Kanje, 1999) and this effect as well seems to be dependent on sex. Indeed, PROG increased Schwann cell proliferation in cultures of segments of rat sciatic nerve from females, but was ineffective in cultures from males (Fex Svenningsen and Kanje, 1999).

The axonal compartment of PNS neurons is also a target for the action of PROG and its metabolites. Thus, PROG affects the expression of neuronal genes involved in the myelination process by Schwann cells. For instance, in co-culture of Schwann cells and 


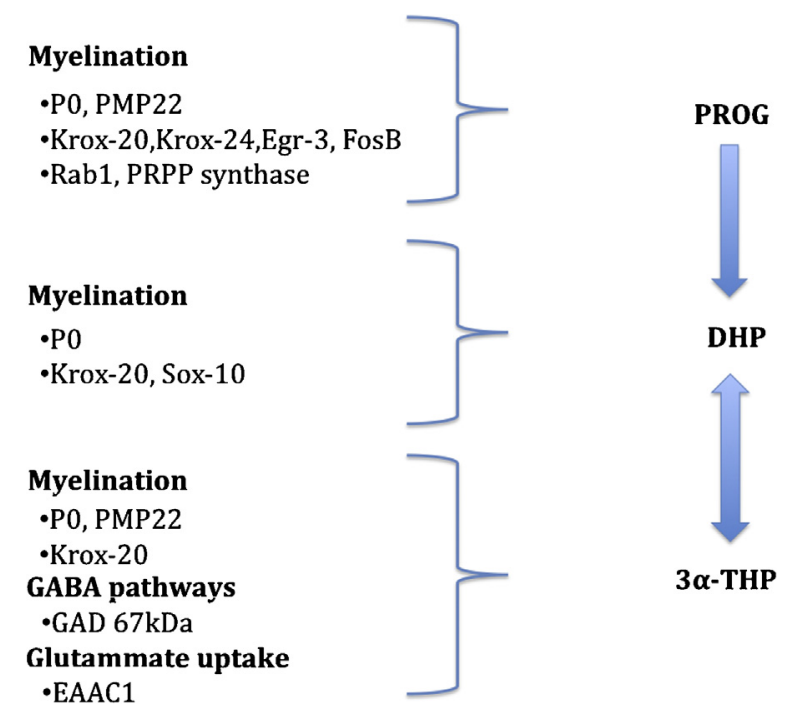

Fig. 3. Physiological effects of progesterone (PROG) and its metabolites in the peripheral nervous system. Details are provided in the text. Dihydroprogesterone (DHP); $3 \alpha, 5 \alpha$-tetrahydroprogesterone ( $3 \alpha$-THP); glycoprotein zero (P0); peripheral myelin protein 22 (PMP22); Ras-like GTP-binding protein (Rap1b); phosphoribosyl diphosphate synthase-associated protein (PRPP); glutamic acid decarboxylase-67 kDa (GAD); excitatory amino acid carrier-1 (EAAC1).

DRG neurons, a small Ras-like GTP-binding protein (Rap 1b) and phosphoribosyl diphosphate synthase-associated protein, which are induced in co-cultures during myelin synthesis, were also induced by PROG treatment (Chan et al., 2000; Rodriguez-Waitkus et al., 2003). Finally, the blockade of PR by mifepristone during development resulted in axonal impairment in the sciatic nerve of male rats (Melcangi et al., 2003b) (Fig. 3).

\section{Levels of progesterone and its derivatives in neurodegenerative diseases}

Different pathologies of the CNS and PNS show sex differences in their incidence, symptomatology and/or neurodegenerative outcome. These include Parkinson's disease, Alzheimer's disease, Huntington's disease, multiple sclerosis, traumatic brain injury, stroke, autism, schizophrenia, depression, anxiety disorders, eating disorders and peripheral neuropathy (Melcangi and Garcia-Segura, 2010). Thus, sex differences in neuroactive steroid levels may represent causative factors for sex differences in the incidence or manifestation of pathologies of the nervous system. Examples of changes in neuroactive steroid levels during neurodegenerative events are shown in Fig. 4.

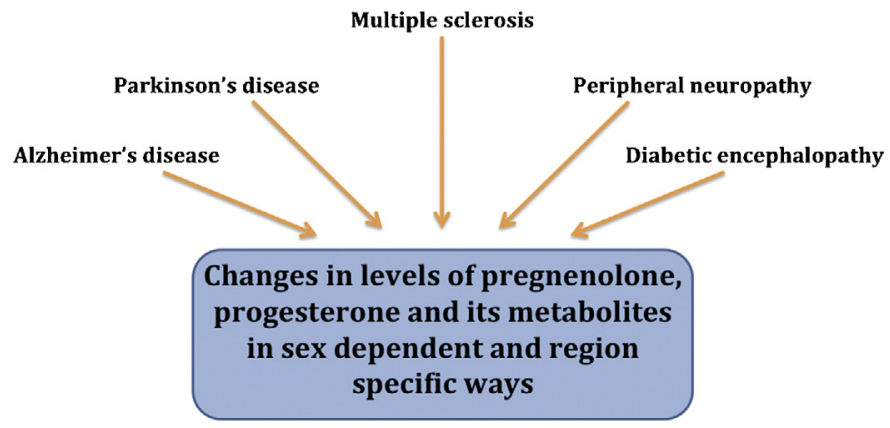

Fig. 4. Examples of neurodegenerative disorders affecting the levels of pregnenolone, progesterone and its metabolites in nervous system. Details are provided in the text.

\subsection{Alzheimer's disease}

In a recent study (Caruso et al., 2013), the levels of neuroactive steroids have been assessed in male brains from a mouse model of Alzheimer's disease (i.e., 3xTg-AD mice). An age-related decrease in the levels of PROG, together with an increase in the levels of its metabolite DHP, was detected in the limbic region of wild type (WT) and 3xTg-AD mice. Concerning PROG metabolites in the limbic region, a significant increase in the levels of DHP and $3 \beta$ THP in 3xTg-AD compared to WT mice was reported. In addition, DHP positively correlated with $3 \alpha$-THP in young $3 \times$ Tg-AD mice, and negatively correlated with $3 \beta-\mathrm{THP}$ in aged $3 \times \mathrm{XTg}-\mathrm{AD}$ mice. These correlations were not detected in WT mice. In contrast, $3 \times T g-A D$ mice did not show the positive correlations in the levels of PREG and DHP and in the levels of $3 \alpha$-THP and $3 \beta$-THP that were detected in young and older WT mice, respectively.

These findings suggest that the metabolism of PROG is altered in the limbic region of 3xTg-AD mice (Caruso et al., 2013). This modification is of outmost importance considering that PROG metabolites have been shown to be neuroprotective (Brinton et al., 2008; Brinton and Wang, 2006; Sun et al., 2012). Indeed, treatment of $3 \times \mathrm{Tg}$-AD mice with $3 \alpha$-THP decreases $\beta$-amyloid accumulation (Chen et al., 2011), reverses cognitive deficits and promotes neurogenesis (Singh et al., 2011; Wang et al., 2010). The protective action of $3 \alpha$-THP may be related with its ability to activate the GABA-A receptor (Melcangi et al., 2008). Moreover, in this context, it is also important to highlight that, as recently reported (Luchetti et al., 2011a,b), the expression of several GABA-A receptor subunits is significantly reduced in post-mortem brain tissue of Alzheimer's disease patients. Indeed, alterations of GABA signals may play an important role in the cognitive and behavioral alterations occurring in Alzheimer's disease (Birzniece et al., 2006; Lanctot et al., 2007). Thus it has been hypothesized that brain alterations in PROG metabolites that modulate GABA-A receptor function, may contribute to the cognitive alterations of Alzheimer's disease patients.

\subsection{Parkinson's disease}

Altered levels of PROG and metabolites have been also observed in Parkinson's disease and corresponding animal models. Relatively high levels of PROG, and its derivatives, DHP and $3 \alpha$-THP, have been detected in the human substantia nigra pars compacta and caudate nucleus, with respect to other brain regions (Bixo et al., 1997), suggesting that substantial synthesis and accumulation of neuroactive steroids may take place in the nigrostriatal system. Moreover, various studies have reported that neuroactive steroids can affect synaptic transmission at the cortico-striatal level, by modulating the striatal release of dopamine (Whittaker et al., 2008). Furthermore, as mentioned above, neuroactive steroids can act as either positive or negative modulators of the GABA-A receptor (Belelli and Lambert, 2005). This class of molecules may, therefore, intervene in the modulation of basal ganglia circuitry activity, where GABAergic transmission plays a crucial role at various points (Blandini et al., 2000).

A significant decrease of PREG in the striatum has been observed after the degeneration of nigrostriatal dopaminergic neurons obtained by the stereotaxic injection of the neurotoxin 6hydroxydopamine (Melcangi et al., 2012). A similar effect was observed in the levels of DHP and $3 \beta$-THP in the striatum and the cerebral cortex. In this context, it is interesting to note that gene expression of $5 \alpha-\mathrm{R}$ (i.e., the enzyme converting PROG into DHP) was decreased in the substantia nigra, as well as in peripheral blood mononuclear cells of Parkinson's disease patients (Luchetti et al., 2010). Decreased DHP levels have also been detected in the cerebrospinal fluid of Parkinson's disease patients (di Michele et al., 2003). 


\subsection{Multiple sclerosis}

It is well know that the incidence, the progression and the severity of multiple sclerosis, an inflammatory, demyelinating disease of the CNS, are affected in a sex-dependent way (Orton et al., 2006; Noonan et al., 2002; Schwendimann and Alekseeva, 2007). Physiological situations characterized by changes in sex steroid plasma levels, such as menstrual cycle, menopause or pregnancy, affect the disease course (Darlington, 2002; El-Etr et al., 2005; Holmqvist et al., 2006; Tomassini and Pozzilli, 2006; Vukusic and Confavreux, 2006; Vukusic et al., 2004), suggesting that these molecules might exert a role in this pathology. Data obtained in a classical experimental model of multiple sclerosis (i.e., experimental autoimmune encephalomyelitis, EAE) have shown that, at acute phase (i.e., 14 days after immunization) the levels of PROG and its metabolites show sex and regional differences in control and EAE nervous system and that a clear difference was also observed between CNS and plasma levels (Giatti et al., 2010). In particular, in agreement with previous observations showing that multiple sclerosis may affect sex steroid plasma levels (Foster et al., 2003; Maccio et al., 2004; Safarinejad, 2008; Tomassini et al., 2005), the levels of PROG and its metabolites DHP and $3 \beta$-THP were reduced in male plasma (Giatti et al., 2010). On the contrary, the only change induced by EAE in female plasma was a decrease in the levels of $3 \alpha$-THP (Giatti et al., 2010).

In addition to the changes in plasma levels, the concentrations of PROG and its metabolites are also altered by EAE in the nervous system (Giatti et al., 2010). Thus, $3 \alpha$-THP levels were significantly increased with EAE in the spinal cord and the cerebral cortex, but only in males. In contrast, the amounts of PROG, DHP and $3 \beta-T H P$ did not show sex differences in the spinal cord and were significantly decreased with EAE in both sexes. However, it is also important to highlight that in the cerebellum and the cerebral cortex these changes were sexually dimorphic, with a decrease occurring only in EAE males. In particular, PROG and $3 \beta$-THP levels were decreased in the cerebellum, while in the cerebral cortex a decrease of PROG and DHP was detected. Altogether, these data suggest that acute phase of EAE modifies PROG and its metabolites in a sex dimorphic way and with regional specificity (Giatti et al., 2010).

An important observation is that the changes observed in plasma in the EAE model did not fully reflect those in the CNS. For instance, the decrease of PREG and the increase of $3 \alpha-T H P$ levels observed in male CNS areas were not observed in plasma. Similarly, the amounts of PROG, DHP and $3 \beta$-THP were decreased in female CNS areas but not in plasma. Thus, plasma neuroactive steroid levels seem to represent an incomplete picture of the changes occurring in the CNS, and consequently cannot be considered accurate biomarkers of the disease.

The effect of EAE on PROG and its metabolite levels shows several dissimilarities between the chronic (i.e., 40 days after immunization) (Caruso et al., 2010a) and the acute phase of the disease (Giatti et al., 2010). Indeed, acute and chronic EAE had similar effects on PROG and DHP levels in the cerebral cortex but different effects in the spinal cord and the cerebellum. Acute and chronic EAE also had a different effect on $3 \alpha$-THP and $3 \beta$-THP levels. Thus, the levels of $3 \alpha$-THP were unchanged in both sexes in spinal cord and cerebral cortex after chronic EAE (Caruso et al., 2010a) while they were increased in both male CNS areas after acute EAE (Giatti et al., 2010). On the other hand, the pattern of $3 \alpha$ THP levels in the cerebellum at the chronic phase was unchanged respect to the acute phase (Caruso et al., 2010a). The amount of $3 \beta$ THP in spinal cord was decreased in both sexes in the acute phase of EAE (Giatti et al., 2010) but return to control levels in the chronic phase (Caruso et al., 2010a). Differences in 3 $\beta$-THP concentration between acute and chronic EAE were also detected in the cerebellum and the cerebral cortex.

\subsection{Peripheral neuropathies}

As demonstrated in several experimental models, the amounts of neuroactive steroids present in peripheral nerves are affected by traumatic injury and pathologies (Melcangi et al., 2011). In particular, in the experimental model of crush injury the levels of PREG, DHP and $3 \alpha$-THP present in the distal portion of injured sciatic nerve were lowered (Roglio et al., 2008). The drop of DHP was not explained by a decrease in the levels of its first precursor (i.e., PROG) that were unchanged, but by a decrease in the expression of the enzyme $5 \alpha-\mathrm{R}$ (Roglio et al., 2008).

Peripheral neuropathy is the most frequent symptomatic complication of diabetes in the nervous system. It is characterized by a spectrum of functional and structural changes in peripheral nerves including axonal degeneration, paranodal demyelination and loss of myelinated fibers and decreased nerve conduction velocity (Sugimoto et al., 2000; Vinik et al., 2000).

Diabetic neuropathy is more frequent in men than in women (ratio male/female 2.9) (Basit et al., 2004; Booya et al., 2005). Moreover, males develop neuropathy earlier than females (Aaberg et al., 2008). Neuropathic pain and negative sensory symptoms are more frequent in females, whereas muscle weakness and atrophy is more frequent in male patients (Kiziltan and Benbir, 2008). Motor nerve conduction abnormalities and ulnar nerve involvement is also more frequent and severe in males (Kiziltan and Benbir, 2008; Kiziltan et al., 2007). In particular, nerve conduction studies indicated that men have lower amplitudes and conduction velocities and longer latencies than female patients (Albers et al., 1996). In streptozotocin (STZ)-treated rats (i.e., an experimental model of diabetes), the paw withdrawal threshold is reduced more in females than in males, suggesting that nociceptive threshold is differently affected in the two sexes (Joseph and Levine, 2003).

Diabetes is also known to influence plasma levels of sex steroids (Babichev et al., 1998; Durant et al., 1998; Leonelli et al., 2007; Roglio et al., 2007; Salonia et al., 2006; Tanaka et al., 2001; van Dam et al., 2003). In the STZ-model the plasma levels of PROG are significantly decreased both in female and male animals. In addition, the amounts of PREG are significantly decreased in the sciatic nerve of male rats, while those of PROG and its metabolites $3 \alpha$-THP and $3 \beta$-THP are decreased in females (Pesaresi et al., 2010b).

Similar sex dimorphic changes have been obtained in other experimental model of peripheral nerve damage. For instance, in the sciatic nerve of PMP22 transgenic rats (i.e., an experimental model of Charcot-Marie-Tooth type $1 \mathrm{~A}$ ) the levels of $3 \beta$-THP, were strongly decreased only in females (Caruso et al., 2008b).

\subsection{Diabetic encephalopathy}

In addition to result in peripheral neuropathy, diabetes may also induce neurophysiological and structural changes at the level of the CNS (i.e., diabetic encephalopathy) (McCall, 2002), which are associated with cognitive deficits and increased risk of dementia, stroke, cerebrovascular and Alzheimer's disease and psychiatric disorders, such as depression and eating disorders (Biessels et al., 2008, 2002; Gispen and Biessels, 2000; Jacobson et al., 2002; Kodl and Seaquist, 2008). These alterations show sex differences in incidence, progression and severity (Andersen et al., 1999; Farace and Alves, 2000; Fratiglioni et al., 1997; Kaye, 2008; Marcus et al., 2008; Niemeier et al., 2007; Simonds and Whiffen, 2003).

Sex differences in the amount of PROG and its derivatives have been detected in the brains of STZ-treated animals (Pesaresi et al., 2010b). In particular, PROG levels show a sex difference in the cerebellum of diabetic rats, decreasing versus control values in 
females, but not in males. The levels of PROG metabolites are impaired in a different way. Indeed, STZ causes a decrease in the levels of DHP and $3 \alpha$-THP in the cerebellum and spinal cord, respectively. However, this decrease was detected in males but not in females. In contrast, $3 \beta$-THP levels were decreased by STZ in the cerebellum of females, but not in the cerebellum of males (Pesaresi et al., 2010b). These findings indicate that in the nervous system diabetes induces, in a sex dimorphic and regionally specific manner, decrease in the levels of PROG as well as in those of its metabolites.

Interestingly, levels of neuroactive steroids, including those of $3 \alpha$-THP are also decreased in cerebral areas of Alzheimer's disease patients (Marx et al., 2006) and in the experimental models of this pathology (see above). A close association between diabetes mellitus and Alzheimer's disease has been proposed (Priyadarshini et al., 2012; Takeda et al., 2011). Indeed, extensive abnormalities of insulin and insulin-like growth factor signaling pathways also occur in this neurodegenerative disorder (Steen et al., 2005). Thus, alterations in neuroactive steroid levels might be interpreted as a common feature of the cognitive impairment occurring in diabetes mellitus and Alzheimer's disease.

\section{Neuroprotective actions of progesterone and its metabolites}

\subsection{Neuroprotective effects in the CNS}

Beside the observation that PROG and its metabolites exert functions relevant for the physiology of the CNS, they are also protective agents in the CNS. PROG has been shown to exert neuroprotective effects in different animal models of neurodegenerative and neurological diseases, including experimental models of Alzheimer's disease (Wang et al., 2008), Parkinson's disease (Bourque et al., 2009; Callier et al., 2001), epilepsy (Frye and Scalise, 2000; Rhodes and Frye, 2004), excitotoxicity (Ciriza et al., 2006; Frye and Walf, 2011), stroke (Chen et al., 1999; Cervantes et al., 2002; Gibson and Murphy, 2004; Sayeed et al., 2007), motoneuron degeneration (Gonzalez Deniselle et al., 2002; Yu, 1989), multiple sclerosis and demyelination (Garay et al., 2007; Giatti et al., 2012b; Ibanez et al., 2003, 2004) and traumatic brain injury (Cutler et al., 2007; Djebaili et al., 2004, 2005). In particular, neuroprotective actions of PROG for traumatic brain injury have been characterized in detail. These include the reduction of brain edema (Roof et al., 1996), mitochondrial dysfunction (Robertson et al., 2006), lipid peroxidation (Roof et al., 1997) and neuronal loss (Robertson et al., 2006; Roof et al., 1994). Furthermore, PROG facilitates cognitive recovery after traumatic brain injury (Roof et al., 1994). Clinical studies on the use of PROG for the treatment of traumatic brain injury in humans are in progress (Stein, 2011). PROG represents also a promising drug for the treatment of spinal cord trauma (Gonzalez et al., 2005; Labombarda et al., 2006a; Thomas et al., 1999).

As it has been previously mentioned for the actions of PROG in the CNS under physiological conditions, reduced PROG metabolites DHP and $3 \alpha$-THP are also involved in the neuroprotective actions of PROG. Thus $3 \alpha$-THP reduces seizures (Frye and Scalise, 2000) and exerts protective actions in stroke (Sayeed et al., 2006), oxygen-glucose deprivation (Ardeshiri et al., 2006) and traumatic brain injury (Djebaili et al., 2004, 2005; He et al., 2004). Furthermore, both DHP and $3 \alpha$-THP mediate the protective action of PROG against excitotoxicity (Ciriza et al., 2004, 2006). Reduced PROG metabolites, and in particular $3 \alpha-$ THP, are also potential candidates for the treatment of mood and anxiety disorders (Biggio et al., 2009; Eser et al., 2008; Turkmen et al., 2011; Wirth, 2011).

\subsubsection{Mechanisms of neuroprotection by PROG and its metabolites in the CNS}

5.1.1.1. Trophic actions and activation of survival pathways. PROG and its metabolites may exert neuroprotection by directly promoting neuronal survival by the activation of signal transduction cascades associated with cell survival, such as the mitogenactivated protein (MAP) kinase and phosphoinositide-3 kinase pathways (Kaur et al., 2007; Nilsen and Brinton, 2002; Singh, 2005) and by the regulation of the expression of proapoptotic and antiapoptotic proteins (Djebaili et al., 2005; Nilsen and Brinton, 2002; Yao et al., 2005). PROG reduces also oxidative stress (Ozacmak and Sayan, 2009) and lipid peroxidation (Roof and Hall, 2000). In addition, the PROG metabolite $3 \alpha$-THP may promote neuroprotection by the inhibition of the mitochondrial permeability transition pore (Sayeed et al., 2009).

Trophic actions of PROG and its metabolites, regulating neuritic growth and synaptic plasticity (Foy et al., 2008; Reyna-Neyra et al., 2002) or promoting neurogenesis under neurodegenerative conditions (Wang et al., 2008) may also contribute to the neuroprotective mechanisms. These trophic actions may be mediate by the regulation by PROG of the synthesis of neurotrophins, such as brain-derived neurotrophic factor, which is upregulated by PROG in the spinal cord (Gonzalez Deniselle et al., 2007; Gonzalez et al., 2005) and in organotypic cultures of the cerebral cortex (Kaur et al., 2007; Singh and Su, 2013b; Su et al., 2012).

Classical intracellular PROG receptors, as well as membrane PROG receptors, are involved in the neuroprotective actions of progesterone (Pang et al., 2013; Singh and Su, 2013a; Su et al., 2012). Furthermore, as mentioned before, PROG neuroprotective actions are also mediated through potentiation of GABA-A receptor activity by its reduced metabolite $3 \alpha$-THP (Ardeshiri et al., 2006).

5.1.1.2. Control of neuroinflammation and gliosis. Neuroinflammation is an important feature that precedes and develops along with several different CNS diseases. Therefore, the effect of PROG and its metabolites on neuroinflammatory pathways has been specifically analyzed (Giatti et al., 2012a). As recently reviewed by Arevalo et al. (2012) several observations have been obtained in vitro, utilizing cultures of microglia or astrocytes exposed to lipopolysaccharide (LPS). These same observations have been extended to animal models reproducing pathological conditions ranging from neuro-immune disease like multiple sclerosis (EAE model) to neurodegenerative conditions like traumatic brain injury and excitotoxicity. Using these models, the anti-inflammatory effects of PROG and its metabolites have been assessed on their ability to reduce the activation of cells involved in the response (astrocytes, microglia for the CNS and macrophages and lymphocytes as peripheral cells invading the CNS) and on the consequent production of inflammatory mediators.

In EAE animals, PROG was able to reduce inflammatory markers, such as microglia activation, IL-1 $\beta$, IL-2 and IL-17 (Giatti et al., 2012b). Anti-inflammatory effects have been also reported after treatment with PROG metabolites. For instance, $3 \alpha$-THP treatment reduces the immunoreactivity of ionized calciumbinding adapter molecule 1 (Iba1), the monocytoid cell marker, and CD3e, a lymphocytic marker, in lumbar spinal cord in a model of EAE (Noorbakhsh et al., 2011). In particular, $3 \alpha$-THP diminishes phorbol ester myristate-induced expression of pro-inflammatory genes in primary monocyte-derived macrophage cultures, while it does not affect antigen specific proliferation of CD4+ T-cells as well as the expression of IFN- $\gamma$ and IL-17 in vitro in the presence of myelin oligodendrocyte glycoprotein (Noorbakhsh et al., 2011). These results together with the absence of monocytoid and lymphocytic markers in the spinal cord suggest that $3 \alpha$-THP 
specifically inhibits the activation of both macrophages and microglia as well as the penetration of circulating lymphocytes and macrophages towards the CNS, thus preventing the exacerbation of the immune response. Consistent with the role of a deregulated inflammatory response in the progression of CNS diseases, $3 \alpha$-THP treatment diminishes EAE severity (Noorbakhsh et al., 2011).

The anti-inflammatory effect of PROG and its metabolites also applies to CNS diseases different in nature from EAE. In experimental models of traumatic brain injury, PROG treatment reduces edema, the accumulation of astrocytes in the cerebral cortex and the hippocampus, the activation of nuclear factor kappa B (NF- $\kappa \mathrm{B})$ and the expression of IL-1 $\beta$ and TNF- $\alpha$ (Pettus et al., 2005). Moreover, PROG attenuates the reactivity of astrocytes and microglia/ macrophages in spinal cord injury models (Garay et al., 2011; Labombarda et al., 2011) and decreases the lesion volume and the expression of IL-1 $\beta$, inducible nitric oxide synthase (Gibson et al., 2008), Iba1 and cyclooxygenase- 2 in ischemic-stroke models (Jiang et al., 2011). Indeed, in ischemic stroke, $3 \alpha$-THP reduces infarct size, and the production of pro-inflammatory cytokines, such as TNF- $\alpha$ and IL-6, and prevents blood brain barrier disruption (Ishrat et al., 2010). Moreover, THP decreases the expression of IL-1 $\beta$, TNF- $\alpha$ (He et al., 2004) after traumatic brain injury and increases CD55, a potent inhibitor of the complement convertases that are activators of the inflammatory cascade (VanLandingham et al., 2007).

PROG and its metabolites DHP and $3 \alpha$-THP also reduce reactive gliosis in the hippocampus of female rats injected with kainic acid (Ciriza et al., 2004). In this animal model of excitotoxicity, the inhibition of PROG metabolizing enzymes (i.e., $5 \alpha-\mathrm{R}$ and $3 \alpha-\mathrm{HSD}$ ) blocked the antigliotic effect of PROG (Ciriza et al., 2006). This is a very interesting finding in the light of the observation that the conversion of PROG into their metabolites is altered in experimental models reproducing different neurological diseases (Melcangi et al., 2012).

Although no direct evidence exists, GABA-A receptors have been evoked to explain part of the anti-inflammatory effect of $3 \alpha-$ THP. Indeed, GABA-A is expressed in resident and circulating monocytoid cells of the immune system (Bhat et al., 2010) as well as in astrocyte and microglia (Lee et al., 2011). Furthermore, GABA suppresses the reactive response of glial cells to inflammatory stimuli, such as LPS and IFN- $\gamma$, by inhibiting the activation of the inflammatory pathways mediated by NF- $\mathrm{KB}$ and p38 MAP kinase (Lee et al., 2011). Nevertheless, since $3 \alpha$-THP can be reversibly converted to DHP (Melcangi et al., 2008), the recruitment of the classical nuclear PR cannot be totally excluded.

5.1.1.3. Remyelination. Examples of stimulatory effects of PROG on myelin proteins and myelin membranes have been also reported in CNS. In this regard, as demonstrated in explant cultures of cerebellar slice, PROG promotes myelination by increasing myelin basic protein (MBP) expression (Ghoumari et al., 2003). PROG also promotes remyelination by oligodendrocytes in vivo. Indeed, MBP expression is increased after treatments with PROG along with $17 \beta$-estradiol in cuprizone-treated animals (i.e., a demyelinating experimental model) (Acs et al., 2009) or with PROG alone in a model of spinal cord injury (Labombarda et al., 2006a, 2009).

In the STZ model of diabetes, the mRNA levels of two isoforms of MBP, 18.5 and $21.5 \mathrm{kDa}$, are decreased in the spinal cord and the treatment with PROG, counteracts this effect (Pesaresi et al., 2010a). Interestingly, metabolism of PROG into DHP by the enzyme $5 \alpha-\mathrm{R}$, seems to exert an important role in such an effect. Indeed, $5 \alpha-\mathrm{R}$ mRNA levels and DHP amounts are both reduced by diabetes in spinal cord, but the treatment with PROG counteracts these effects. Moreover, treatment with DHP is able to mimic the effect of PROG on MBP gene expression, suggesting that the effects of PROG are due to its enzymatic conversion into DHP (Pesaresi et al., 2010a).

\subsection{Neuroprotective effects in the PNS}

The protective effects of PROG and its metabolites have been also explored with success in the PNS (Melcangi et al., 2011). For instance, aging induces important biochemical and morphological changes in peripheral nerves (Azcoitia et al., 2003; Melcangi et al., 2003a). PROG or its derivatives are able to stimulate the low expression of P0 and PMP22 in the sciatic nerve of aged rats (Melcangi et al., 1998, 2003a, 2000b). Moreover, they have also clear beneficial effects on the number and shape of myelinated fibers as well as on the frequency of myelin abnormalities (Azcoitia et al., 2003; Melcangi et al., 2003a).

Protective and regenerative effects of PROG and its metabolites have been well characterized in experimental models of degeneration occurring after physical injury of peripheral nerves. For instance, (1) PROG or DHP, increase gene expression of PO after nerve transection (Melcangi et al., 2000a); (2) PREG and PROG counteract the decrease of the amounts of myelin membranes induced by a cryolesion in the sciatic nerve of the mouse (Koenig et al., 1995); (3) In guided regeneration of facial nerve of rabbit, PROG induces an increase in the number of Schwann cell nuclei, of nonmyelinated and myelinated nerve fibers (with increase also in their diameters), as well as in the g-ratio of myelinated nerve fibers (Chavez-Delgado et al., 2005) and (4) In crush injury model, DHP and/or PROG counteract biochemical alterations (i.e., myelin proteins and $\mathrm{Na}^{+}, \mathrm{K}^{+}$ATPase pump) and stimulate reelin gene expression. These two neuroactive steroids also counteract nociception impairment, and DHP treatment significantly decreases the up-regulation of myelinated fibres' density occurring in crushed nerves (Roglio et al., 2008).

Effects of PROG and its derivatives have been also evaluated in an experimental model of chemotherapy-induced peripheral neurotoxicity, such as those due to docetaxel (Roglio et al., 2009). In particular, treatment with DHP or its precursor, PROG, counteracts docetaxel-induced neuropathy, preventing nerve conduction velocity and thermal threshold changes, and degeneration of skin nerves in the footpad. PROG and DHP also counteract the changes in gene expression of several myelin proteins, such as P0, PMP22, myelin and lymphocyte-associated protein and MBP induced by docetaxel in the sciatic nerve. Most nerve abnormalities observed during the treatment with docetaxel spontaneously recovered after drug withdrawal, similarly to what occurs in patients. However, results of midterm follow-up experiments indicate that animals treated with DHP or PROG show a faster recovery (Roglio et al., 2009).

Neuropathic pain is another important consequence of peripheral nerve damage. PROG metabolites exert a beneficial effect also on this component, since both DHP and $3 \alpha$-THP suppress neuropathic symptoms (allodynia/hyperalgesia) evoked by antineoplastic drugs, such as vincristine (Meyer et al., 2010) or oxaliplatin (Meyer et al., 2011).

Another experimental model in which protective effects of PROG and its metabolites have been ascertained is diabetic neuropathy. Thus, in STZ-treated rats, PROG or its derivatives improve sciatic nerve conduction velocity, myelin protein mRNA levels (i.e., P0 and PMP22), $\mathrm{Na}^{+}, \mathrm{K}^{+}$-ATPase activity, thermal threshold, skin innervation density (Leonelli et al., 2007) and counteract the increase in the number of fibers with myelin infoldings (Veiga et al., 2006).

\section{Pharmacological approaches to increase the levels of progesterone metabolites during neurodegeneration}

The finding of altered levels of neuroactive steroids in several experimental models of neurodegeneration and the beneficial effects for the nervous system of the treatments with these molecules, suggest possible therapies based on neuroactive 
steroids themselves or with synthetic ligands able to interact with their receptors. However, an alternative strategy for neurodegenerative disorders could be to increase the levels of neuroactive steroids directly in the nervous system. This strategy may avoid possible endocrine side effects exerted by the systemic treatment with neuroactive steroids. With this perspective, ligands of TSPO, with the capacity to increase the levels of PREG and consequently those of the following neuroactive steroids (Papadopoulos et al., 2006a,b), may represent a promising option. The effects of these molecules have been assessed in male diabetic animals. As observed in STZ model, Ro5-4864 (i.e., a synthetic ligand of TSPO), increases neuroactive steroid levels in sciatic nerve of male diabetic animals and exerts neuroprotective effects (Fig. 5). In particular, the treatment with the ligand was able to significantly stimulate the low levels of PREG and PROG observed in the sciatic nerves of diabetic rats and to counteract neurophysiological, biochemical and neuropathological changes occurring in this experimental model (Giatti et al., 2009). Thus, TSPO activation was effective in reducing the severity of diabetic neuropathy through a local increase of neuroactive steroid levels.

Another possible strategy could be the activation of the liver $\mathrm{X}$ receptor (LXR) (Fig. 5). Indeed using a synthetic ligand, such as GW3965, an increase of neuroactive steroid levels, such as PREG, PROG and DHP occurs in the sciatic nerve of male diabetic rats. In addition, GW3965 protects the nerve from diabetic neuropathy (Cermenati et al., 2010). TSPO and LXR ligands are also effective in the CNS (Fig. 5). Data obtained have indicated that the treatment with either Ro5-4864 or with GW3965 induced an increase in the levels of PROG and its metabolites in the spinal cord, the cerebellum and the cerebral cortex of STZ-male rats, but not in

\section{Sciatic nerve}
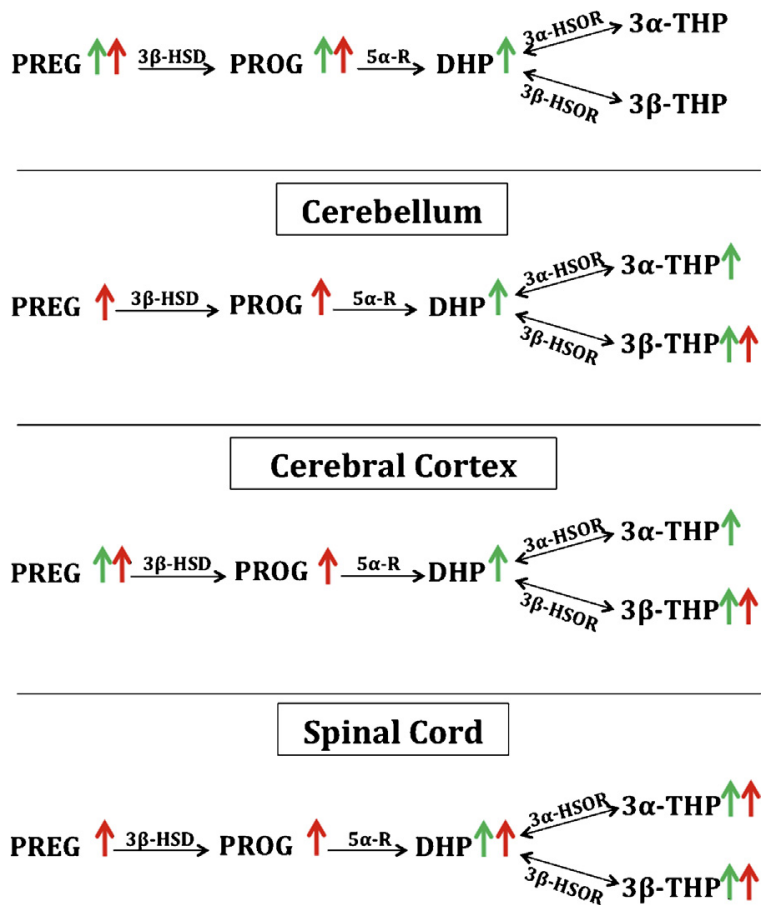

Fig. 5. Effect of GW3965 (green arrow) and Ro5-4864 (red arrow) on the levels of pregnenolone (PREG), progesterone (PROG) and its metabolites in sciatic nerve and central nervous system areas of male diabetic animals. Details are provided in the text. Cholesterol (Chol); translocator protein $18 \mathrm{kDa}$ (TSPO); Steroidogenic acute regulatory protein (StAR); dihydroprogesterone (DHP); $3 \alpha, 5 \alpha$-tetraidroprogesterone ( $3 \alpha$-THP);

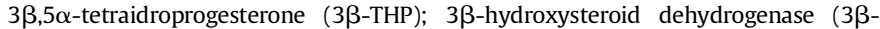
HSD); $5 \alpha$-reductase $(5 \alpha-R)$; $3 \alpha$-hydroxysteroid oxidoreductase ( $3 \alpha$-HSOR); $3 \beta$ hydroxysteroid oxidoreductase ( $3 \beta-\mathrm{HSOR})$. the CNS of non-diabetic animals (Mitro et al., 2012). In particular, the activation of LXRs seems to be very interesting, because, at variance to Ro5-4864, GW3965 treatment did not induce significant changes in the plasma concentrations of neuroactive steroids. Therefore, GW3965 increases neuroactive steroid levels in the CNS avoiding modifications in their plasma levels and their consequent peripheral effects, one of the major limits of a neuroprotective therapy based on neuroactive steroids themselves. Moreover, GW3965 treatment, in comparison to that with Ro5-4864, seems to be more specific in increasing the amounts of PROG and its metabolites (Mitro et al., 2012). In this context, it is important to note that treatment with DHP was able to counteract the decrease of expression of MBP observed in the spinal cord of diabetic animals (Pesaresi et al., 2010a) and that GW3965 treatment induced an increase of DHP in the spinal cord of STZtreated male rats associated with an increase of MBP expression in the same nervous structure (Mitro et al., 2012). In conclusion, these findings suggest that the pharmacological activation of LXR to induce steroidogenesis in the CNS may represent a therapeutic approach to counteract neurophysiological and structural changes induced by diabetes and may be by other pathological conditions.

\section{Conclusions}

The studies reviewed here indicate that PROG and its metabolites exert a wide range of actions under physiological conditions, regulating neuronal and glial development, plasticity and function. Physiological actions of PROG and its metabolites not only play a major role in the control of neuroendocrine and behavioral events associated with reproduction, but also have an impact on mood and affection. As we have seen in the previous pages, recent studies have shown that local PROG synthesis in hypothalamic astrocytes is modulated by physiological changes in the levels of the ovarian hormone estradiol during the estrous cycle. This indicates that the levels of PROG and its metabolites can be modified in the nervous system under some physiological circumstances. However, we still have a very incomplete picture on how the levels of PROG and its metabolites are regulated in the nervous system under physiological conditions and on the consequence of these changes for neural function. In particular, it is important to determine the changes in the levels of PROG and its metabolites in the nervous system at key life stages, such as perinatal development, puberty, reproductive cycles, pregnancy, postpartum period, aging and menopause. Interestingly, the levels of PROG and its metabolites in the nervous system change with regional specificity after gonadectomy, suggesting that hormonal changes associated to the above mentioned life stages may impact on the levels of these neuroactive steroids which, in turn, may cause modifications in mood, anxiety and affection.

The functional consequences of the regional-specific changes in the nervous tissue levels of PROG and its metabolites under pathological conditions should also be explored. It may be assumed that the alteration in the local levels of PROG and its metabolites in the CNS along the course of neurological and neuropsychiatric diseases might contribute to the progression of the pathology. In particular, as it has been mentioned above, a decrease in the nervous tissue levels of PROG and DHP, together with an alteration in the levels of $3 \alpha$-THP and $3 \beta$-THP, are common observations in several experimental models of neurodegeneration. These changes may increase neural damage due to the impairment in the endogenous protective mechanisms activated by PROG and its metabolites and by an altered regulation of GABA-A receptor due to the imbalance between $3 \alpha$-THP and $3 \beta$-THP levels. However, it can not be excluded that at least in some cases, such as the increase in the levels of $3 \alpha$-THP observed in the spinal cord and the cerebral cortex during 
the acute phase of EAE in male rats, the modifications may represent an adaptive endogenous neuroprotective response.

Another important consideration is that the levels of PROG and its metabolites show a sex dimorphism in the CNS and PNS and respond to modifications in peripheral levels of steroid hormones and to pathological conditions with a sex-dimorphic pattern. These sex differences in neurosteroid levels may be related with the reported sex differences in the incidence, symptomatology and/or neurodegenerative outcome of different neurological and affective and psychiatric disorders. These include Parkinson's disease, Alzheimer's disease, Huntington's disease, multiple sclerosis, traumatic brain injury, stroke, anxiety and eating disorders, autism, schizophrenia, depression, and peripheral neuropathy. Therefore, it is important to consider the sex dimorphic levels of PROG and its metabolites in the nervous system to design sexspecific therapeutic approaches. These therapeutic approaches may include pharmacological treatments aimed to increase the levels of PROG and its metabolites in the nervous system.

Finally, the importance of PROG reduced metabolites for the physiological actions and neuroprotective mechanisms of PROG call for the consideration of the possible consequences for human health of drugs that may interfere with PROG metabolism. In this regard it is important to determine whether the inhibition of PROG metabolism contributes to the side effects reported in some men that have been treated with $5 \alpha$-reductase inhibitors (Irwig, 2012a,b).

\section{Acknowledgment}

The financial support of Fondazione CARIPLO (Rif. 2012-0547) to R. C. Melcangi is gratefully acknowledged.

\section{References}

Aaberg, M.L., Burch, D.M., Hud, Z.R., Zacharias, M.P., 2008. Gender differences in the onset of diabetic neuropathy. Journal of Diabetes and its Complications 22, 8387.

Acs, P., Kipp, M., Norkute, A., Johann, S., Clarner, T., Braun, A., Berente, Z., Komoly, S. Beyer, C., 2009. 17beta-estradiol and progesterone prevent cuprizone provoked demyelination of corpus callosum in male mice. Glia 57, 807-814.

Albers, J.W., Brown, M.B., Sima, A.A., Greene, D.A., 1996. Nerve conduction measure in mild diabetic neuropathy in the Early Diabetes Intervention Trial: the effects of age, sex, type of diabetes, disease duration, and anthropometric factors Tolrestat Study Group for the Early Diabetes Intervention Trial. Neurology 46, 85-91.

Amorim, M.A., Guerra-Araiza, C., Pernia, O., da Cruz e Silva, E.F., Garcia-Segura, L.M., 2010. Progesterone regulates the phosphorylation of protein phosphatases in the brain. Journal of Neuroscience Research 88, 2826-2832.

Andersen, K., Launer, L.J., Dewey, M.E., Letenneur, L., Ott, A., Copeland, J.R., Dartigues, J.F., Kragh-Sorensen, P., Baldereschi, M., Brayne, C., Lobo, A., MartinezLage, J.M., Stijnen, T., Hofman, A., 1999. Gender differences in the incidence of $\mathrm{AD}$ and vascular dementia: The EURODEM Studies EURODEM Incidence Research Group. Neurology 53, 1992-1997.

Ardeshiri, A., Kelley, M.H., Korner, I.P., Hurn, P.D., Herson, P.S., 2006. Mechanism of progesterone neuroprotection of rat cerebellar Purkinje cells following oxygenglucose deprivation. European Journal of Neuroscience 24, 2567-2574.

Arevalo, M.A., Santos-Galindo, M., Acaz-Fonseca, E., Azcoitia, I., Garcia-Segura, L.M., 2012. Gonadal hormones and the control of reactive gliosis. Hormones and Behavior 63, 216-221.

Azcoitia, I., Leonelli, E., Magnaghi, V., Veiga, S., Garcia-Segura, L.M., Melcangi, R.C., 2003. Progesterone and its derivatives dihydroprogesterone and tetrahydroprogesterone reduce myelin fiber morphological abnormalities and myelin fiber loss in the sciatic nerve of aged rats. Neurobiology of Aging 24, 853-860.

Babichev, V.N., Adamskaya, E.I., Kuznetsova, T.A., Shishkina, I.V., 1998. Neuroendocrine control of the gonadotropic function of the hypophysis in experimental diabetes. Neuroscience and Behavioral Physiology 28, 1-7.

Banks, J.A., Freeman, M.E., 1980. Inhibition of the daily LH release mechanism by progesterone acting at the hypothalamus. Biology of Reproduction 22, 217-222

Barfield, R.J., Glaser, J.H., Rubin, B.S., Etgen, A.M., 1984. Behavioral effects of progestin in the brain. Psychoneuroendocrinology 9, 217-231.

Barraclough, C.A., Camp, P., Weiland, N., Akabori, A., 1986. Stimulatory versus inhibitory effects of progesterone on estrogen-induced phasic LH and prolactin secretion correlated with estrogen nuclear and progestin cytosol receptor concentrations in brain and pituitary gland. Neuroendocrinology 42, 6-14.

Bartolami, S., Auge, C., Travo, C., Venteo, S., Knipper, M., Sans, A., 2003. Vestibular Schwann cells are a distinct subpopulation of peripheral glia with specific sensitivity to growth factors and extracellular matrix components. Journal of Neurobiology 57, 270-290.

Basit, A., Hydrie, M.Z., Hakeem, R., Ahmedani, M.Y., Masood, Q., 2004. Frequency of chronic complications of type II diabetes. Journal of the College of Physicians and Surgeons-Pakistan 14, 79-83.

Belelli, D., Lambert, J.J., 2005. Neurosteroids: endogenous regulators of the GABA(A) receptor. Nature Reviews Neuroscience 6, 565-575.

Bhat, R., Axtell, R., Mitra, A., Miranda, M., Lock, C., Tsien, R.W., Steinman, L., 2010. Inhibitory role for GABA in autoimmune inflammation. Proceedings of National Academy of Sciences United States of America 107, 2580-2585.

Biessels, G.J., Deary, I.J., Ryan, C.M., 2008. Cognition and diabetes: a lifespan perspective. Lancet Neurology 7, 184-190.

Biessels, G.J., van der Heide, L.P., Kamal, A., Bleys, R.L., Gispen, W.H., 2002. Ageing and diabetes: implications for brain function. European Journal of Pharmacology 441, 1-14.

Biggio, G., Cristina Mostallino, M., Follesa, P., Concas, A., Sanna, E., 2009. GABA(A) receptor function and gene expression during pregnancy and postpartum. International Review of Neurobiology 85, 73-94.

Billiar, R.B., Little, B., Kline, I., Reier, P., Takaoka, Y., White, R.J., 1975. The metabolic clearance rate, head and brain extractions, and brain distribution and metabolism of progesterone in the anesthetized, female monkey (Macaca mulatta). Brain Research 94, 99-113.

Birzniece, V., Backstrom, T., Johansson, I.M., Lindblad, C., Lundgren, P., Lofgren, M., Olsson, T., Ragagnin, G., Taube, M., Turkmen, S., Wahlstrom, G., Wang, M.D., Wihlback, A.C., Zhu, D., 2006. Neuroactive steroid effects on cognitive functions with a focus on the serotonin and GABA systems. Brain Research Review 51, 212-239.

Bitran, D., Hilvers, R.J., Kellogg, C.K., 1991. Anxiolytic effects of 3 alpha-hydroxy-5 alpha[beta]-pregnan-20-one: endogenous metabolites of progesterone that are active at the GABAA receptor. Brain Research 561, 157-161.

Bixo, M., Andersson, A., Winblad, B., Purdy, R.H., Backstrom, T., 1997. Progesterone, 5alpha-pregnane-3,20-dione and 3alpha-hydroxy-5alpha-pregnane-20-one in specific regions of the human female brain in different endocrine states. Brain Research 764, 173-178.

Blandini, F., Nappi, G., Tassorelli, C., Martignoni, E., 2000. Functional changes of the basal ganglia circuitry in Parkinson's disease. Progress in Neurobiology 62, 6388.

Booya, F., Bandarian, F., Larijani, B., Pajouhi, M., Nooraei, M., Lotfi, J., 2005. Potential risk factors for diabetic neuropathy: a case control study. BMC Neurology 5, 24.

Bourque, M., Dluzen, D.E., Di Paolo, T., 2009. Neuroprotective actions of sex steroids in Parkinson's disease. Frontiers in Neuroendocrinology 30, 142-157.

Brinton, R.D., Thompson, R.F., Foy, M.R., Baudry, M., Wang, J., Finch, C.E., Morgan, T.E., Pike, C.J., Mack, W.J., Stanczyk, F.Z., Nilsen, J., 2008. Progesterone receptors: form and function in brain. Frontiers in Neuroendocrinology 29, 313-339.

Brinton, R.D., Wang, J.M., 2006. Therapeutic potential of neurogenesis for prevention and recovery from Alzheimer's disease: allopregnanolone as a proof of concept neurogenic agent. Current Alzheimers Research 3, 185-190.

Callier, S., Morissette, M., Grandbois, M., Pelaprat, D., Di Paolo, T., 2001. Neuroprotective properties of 17 beta-estradiol, progesterone, and raloxifene in MPTP C57Bl/6 mice. Synapse 41, 131-138.

Caruso, D., Barron, A.M., Brown, M.A., Abbiati, F., Carrero, P., Pike, C.J., Garcia-Segura, L.M., Melcangi, R.C., 2013. Age-related changes in neuroactive steroid levels in 3xTg-AD mice. Neurobiology of Aging 34, 1080-1089.

Caruso, D., D’Intino, G., Giatti, S., Maschi, O., Pesaresi, M., Calabrese, D., GarciaSegura, L.M., Calza, L., Melcangi, R.C., 2010a. Sex-dimorphic changes in neuroactive steroid levels after chronic experimental autoimmune encephalomyelitis. Journal of Neurochemistry 114, 921-932.

Caruso, D., Pesaresi, M., Maschi, O., Giatti, S., Garcia-Segura, L.M., Melcangi, R.C. 2010b. Effects of short- and long-term gonadectomy on neuroactive steroid levels in the central and peripheral nervous system of male and female rats. Journal of Neuroendocrinology 22, 1137-1147.

Caruso, D., Scurati, S., Maschi, O., De Angelis, L., Roglio, I., Giatti, S., Garcia-Segura, L.M., Melcangi, R.C., 2008a. Evaluation of neuroactive steroid levels by liquid chromatography-tandem mass spectrometry in central and peripheral nervous system: effect of diabetes. Neurochemistry International 52, 560-568.

Caruso, D., Scurati, S., Roglio, I., Nobbio, L., Schenone, A., Melcangi, R.C., 2008b. Neuroactive Steroid Levels in a transgenic rat model of CMT1A Neuropathy. Journal of Molecular Neuroscience 34, 249-253.

Cavarretta, I.T., Martini, L., Motta, M., Smith, C.L., Melcangi, R.C., 2004. SRC-1 is involved in the control of the gene expression of myelin protein Po. Journal of Molecular Neuroscience 24, 217-226.

Cermenati, G., Giatti, S., Cavaletti, G., Bianchi, R., Maschi, O., Pesaresi, M., Abbiati, F., Volonterio, A., Saez, E., Caruso, D., Melcangi, R.C., Mitro, N., 2010. Activation of the liver $\mathrm{X}$ receptor increases neuroactive steroid levels and protects from diabetes-induced peripheral neuropathy. Journal of Neuroscience 30, 1189611901.

Cervantes, M., Gonzalez-Vidal, M.D., Ruelas, R., Escobar, A., Morali, G., 2002. Neuroprotective effects of progesterone on damage elicited by acute global cerebral ischemia in neurons of the caudate nucleus. Archives of Medical Research 33, 6-14.

Chan, J.R., Phillips 2nd, L.J., Glaser, M., 1998. Glucocorticoids and progestins signal the initiation and enhance the rate of myelin formation. Proceedings of National Academy of Sciences United States of America 95, 10459-10464.

Chan, J.R., Rodriguez-Waitkus, P.M., Ng, B.K., Liang, P., Glaser, M., 2000. Progesterone synthesized by Schwann cells during myelin formation regulates neuronal gene expression. Molecular Biology of Cell 11, 2283-2295. 
Chavez-Delgado, M.E., Gomez-Pinedo, U., Feria-Velasco, A., Huerta-Viera, M., Castaneda, S.C., Toral, F.A., Parducz, A., Anda, S.L., Mora-Galindo, J., Garcia-Estrada, J., 2005. Ultrastructural analysis of guided nerve regeneration using progesterone- and pregnenolone-loaded chitosan prostheses. Journal of Biomedical Materials Research B Applied Biomaterials 74, 589-600.

Chen, J., Chopp, M., Li, Y., 1999. Neuroprotective effects of progesterone after transient middle cerebral artery occlusion in rat. Journal of Neurological Sciences 171, 24-30.

Chen, S., Wang, J.M., Irwin, R.W., Yao, J., Liu, L., Brinton, R.D., 2011. Allopregnanolone promotes regeneration and reduces beta-amyloid burden in a preclinical model of Alzheimer's disease. PLoS One 6, e24293.

Ciriza, I., Azcoitia, I., Garcia-Segura, L.M., 2004. Reduced progesterone metabolites protect rat hippocampal neurones from kainic acid excitotoxicity in vivo. Journal of Neuroendocrinology 16, 58-63.

Ciriza, I., Carrero, P., Frye, C.A., Garcia-Segura, L.M., 2006. Reduced metabolites mediate neuroprotective effects of progesterone in the adult rat hippocampus The synthetic progestin medroxyprogesterone acetate (Provera) is not neuroprotective. Journal of Neurobiology 66, 916-928.

Coirini, H., Gouezou, M., Liere, P., Delespierre, B., Pianos, A., Eychenne, B., Schumacher, M., Guennoun, R., 2002. 3 Beta-hydroxysteroid dehydrogenase expression in rat spinal cord. Neuroscience 113, 883-891.

Corpechot, C., Young, J., Calvel, M., Wehrey, C., Veltz, J.N., Touyer, G., Mouren, M., Prasad, V.V., Banner, C., Sjovall, J., Baulieu, E.E., Robel, P., 1993. Neurosteroids: 3 alpha-hydroxy-5 alpha-pregnan-20-one and its precursors in the brain, plasma, and steroidogenic glands of male and female rats. Endocrinology 133, 10031009.

Cutler, S.M., Cekic, M., Miller, D.M., Wali, B., VanLandingham, J.W., Stein, D.G., 2007. Progesterone improves acute recovery after traumatic brain injury in the aged rat. Journal of Neurotrauma 24, 1475-1486.

D'Urso, D., Brophy, P.J., Staugaitis, S.M., Gillespie, C.S., Frey, A.B., Stempak, J.G., Colman, D.R., 1990. Protein zero of peripheral nerve myelin: biosynthesis, membrane insertion, and evidence for homotypic interaction. Neuron 4 , 449-460.

Darlington, C., 2002. Multiple sclerosis and gender. Current Opinion in Investigational Drugs 3, 911-914.

di Michele, F., Longone, P., Romeo, E., Lucchetti, S., Brusa, L., Pierantozzi, M., Bassi, A., Bernardi, G., Stanzione, P., 2003. Decreased plasma and cerebrospinal fluid content of neuroactive steroids in Parkinson's disease. Neurological Sciences 24, $172-173$.

Djebaili, M., Guo, Q., Pettus, E.H., Hoffman, S.W., Stein, D.G., 2005. The neurosteroids progesterone and allopregnanolone reduce cell death, gliosis, and functional deficits after traumatic brain injury in rats. Journal of Neurotrauma 22, 106-118.

Djebaili, M., Hoffman, S.W., Stein, D.G., 2004. Allopregnanolone and progesterone decrease cell death and cognitive deficits after a contusion of the rat pre-frontal cortex. Neuroscience 123, 349-359.

Durant, S., Christeff, N., Coulaud, J., Nunez, E.A., Dardenne, M., Homo-Delarche, F., 1998. Basal concentrations of various steroids in the nonobese diabetic (NOD) mouse and effect of immobilization stress. Autoimmunity 28, 249-258.

El-Etr, M., Vukusic, S., Gignoux, L., Durand-Dubief, F., Achiti, I., Baulieu, E.E., Confavreux, C., 2005. Steroid hormones in multiple sclerosis. Journal of Neurological Sciences 233, 49-54.

Eser, D., Baghai, T.C., Schule, C., Nothdurfter, C., Rupprecht, R., 2008. Neuroactive steroids as endogenous modulators of anxiety. Current Pharmaceutical Design $14,3525-3533$

Farace, E., Alves, W.M., 2000. Do women fare worse: a metaanalysis of gender differences in traumatic brain injury outcome. Journal of Neurosurgery 93, 539545.

Fex Svenningsen, A., Kanje, M., 1999. Estrogen and progesterone stimulate Schwann cell proliferation in a sex- and age-dependent manner. Journal of Neuroscience Research 57, 124-130.

Follesa, P., Concas, A., Porcu, P., Sanna, E., Serra, M., Mostallino, M.C., Purdy, R.H., Biggio, G., 2001. Role of allopregnanolone in regulation of GABA(A) receptor plasticity during long-term exposure to and withdrawal from progesterone. Brain Research Brain Research Reviews 37, 81-90.

Foster, S.C., Daniels, C., Bourdette, D.N., Bebo Jr., B.F., 2003. Dysregulation of the hypothalamic-pituitary-gonadal axis in experimental autoimmune encephalomyelitis and multiple sclerosis. Journal of Neuroimmunology 140, 78-87.

Foy, M.R., Akopian, G., Thompson, R.F., 2008. Progesterone regulation of synaptic transmission and plasticity in rodent hippocampus. Learning and Memory 15 820-822.

Fratiglioni, L., Viitanen, M., von Strauss, E., Tontodonati, V., Herlitz, A., Winblad, B., 1997. Very old women at highest risk of dementia and Alzheimer's disease: incidence data from the Kungsholmen Project, Stockholm. Neurology 48, 132 138.

Frye, C.A., Scalise, T.J., 2000. Anti-seizure effects of progesterone and 3alpha,5alphaTHP in kainic acid and perforant pathway models of epilepsy. Psychoneuroendocrinology 25, 407-420.

Frye, C.A., Walf, A., 2011. Progesterone, administered before kainic acid, prevents decrements in cognitive performance in the Morris Water Maze. Developmental Neurobiology 71, 142-152.

Frye, C.A., Walf, A.A., 2008. Membrane actions of progestins at dopamine type 1-like and GABAA receptors involve downstream signal transduction pathways. Steroids 73, 906-913.

Garay, L., Deniselle, M.C., Lima, A., Roig, P., De Nicola, A.F., 2007. Effects of progesterone in the spinal cord of a mouse model of multiple sclerosis. The Journal of Steroid Biochemistry and Molecular Biology 107, 228-237.
Garay, L., Tungler, V., Deniselle, M.C., Lima, A., Roig, P., De Nicola, A.F., 2011 Progesterone attenuates demyelination and microglial reaction in the lysolecithin-injured spinal cord. Neuroscience 192, 588-597.

Garcia-Segura, L.M., Chowen, J.A., Parducz, A., Naftolin, F., 1994. Gonadal hormones as promoters of structural synaptic plasticity: cellular mechanisms. Progress in Neurobiology 44, 279-307.

Garcia-Segura, L.M., Melcangi, R.C., 2006. Steroids and glial cell function. Glia 54, 485-498.

Ghoumari, A.M., Baulieu, E.E., Schumacher, M., 2005. Progesterone increases oligodendroglial cell proliferation in rat cerebellar slice cultures. Neuroscience 135, 47-58.

Ghoumari, A.M., Ibanez, C., El-Etr, M., Leclerc, P., Eychenne, B., O’Malley, B.W. Baulieu, E.E., Schumacher, M., 2003. Progesterone and its metabolites increase myelin basic protein expression in organotypic slice cultures of rat cerebellum. Journal of Neurochemistry 86, 848-859.

Giachino, C., Galbiati, M., Fasolo, A., Peretto, P., Melcangi, R., 2003. Neurogenesis in the subependymal layer of the adult rat: a role for neuroactive derivatives of progesterone. Annals of the New York Academy of Sciences 1007, 335-339.

Giatti, S., Boraso, M., Abbiati, F., Ballarini, E., Calabrese, D., Santos-Galindo, M., Rigolio, R., Pesaresi, M., Caruso, D., Viviani, B., Cavaletti, G., Garcia-Segura, L.M. Melcangi, R.C., 2013. Multimodal analysis in acute and chronic experimental autoimmune encephalomyelitis. Journal of Neuroimmune Pharmacology 8 , $238-250$.

Giatti, S., Boraso, M., Melcangi, R.C., Viviani, B., 2012a. Neuroactive steroids, their metabolites and neuroinflammation. Journal of Molecular Endocrinology 49, R125-R134.

Giatti, S., Caruso, D., Boraso, M., Abbiati, F., Ballarini, E., Calabrese, D., Pesaresi, M., Rigolio, R., Santos-Galindo, M., Viviani, B., Cavaletti, G., Garcia-Segura, L.M. Melcangi, R.C., 2012b. Neuroprotective effects of progesterone in chronic experimental autoimmune encephalomyelitis. Journal of Neuroendocrinology $24,851-861$.

Giatti, S., D’Intino, G., Maschi, O., Pesaresi, M., Garcia-Segura, L.M., Calza, L., Caruso D., Melcangi, R.C., 2010. Acute experimental autoimmune encephalomyelitis induces sex dimorphic changes in neuroactive steroid levels. Neurochemistry International 56, 118-127.

Giatti, S., Pesaresi, M., Cavaletti, G., Bianchi, R., Carozzi, V., Lombardi, R., Maschi, O. Lauria, G., Garcia-Segura, L.M., Caruso, D., Melcangi, R.C., 2009. Neuroprotective effects of a ligand of translocator protein-18 kDa (Ro5-4864) in experimental diabetic neuropathy. Neuroscience 164, 520-529.

Gibson, C.L., Gray, L.J., Bath, P.M., Murphy, S.P., 2008. Progesterone for the treatment of experimental brain injury; a systematic review. Brain 131, 318-328.

Gibson, C.L., Murphy, S.P., 2004. Progesterone enhances functional recovery after middle cerebral artery occlusion in male mice. Journal of Cerebral Blood Flow \& Metabolism 24, 805-813.

Gispen, W.H., Biessels, G.J., 2000. Cognition and synaptic plasticity in diabetes mellitus. Trends in Neurosciences 23, 542-549.

Giuliani, F.A., Escudero, C., Casas, S., Bazzocchini, V., Yunes, R., Laconi, M., Cabrera, R. 2013. Allopregnanolone and puberty: Modulatory effect on glutamate and GABA release and expression of 3alpha-hydroxysteroid oxidoreductase in the hypothalamus of female rats. Neuroscience 243, 64-75.

Gonzalez Deniselle, M.C., Garay, L., Gonzalez, S., Saravia, F., Labombarda, F., Guennoun, R., Schumacher, M., De Nicola, A.F., 2007. Progesterone modulates brainderived neurotrophic factor and choline acetyltransferase in degenerating Wobbler motoneurons. Experimental Neurology 203, 406-414.

Gonzalez Deniselle, M.C., Lopez-Costa, J.J., Saavedra, J.P., Pietranera, L., Gonzalez S.L., Garay, L., Guennoun, R., Schumacher, M., De Nicola, A.F., 2002. Progesterone neuroprotection in the Wobbler mouse, a genetic model of spinal cord motor neuron disease. Neurobiology of Disease 11, 457-468.

Gonzalez, S.L., Labombarda, F., Deniselle, M.C., Mougel, A., Guennoun, R., Schumacher, M., De Nicola, A.F., 2005. Progesterone neuroprotection in spinal cord trauma involves up-regulation of brain-derived neurotrophic factor in motoneurons. The Journal of Steroid Biochemistry and Molecular Biology 94, 143-149.

Groyer, G., Eychenne, B., Girard, C., Rajkowski, K., Schumacher, M., Cadepond, F., 2006. Expression and functional state of the corticosteroid receptors and 11 beta-hydroxysteroid dehydrogenase type 2 in Schwann cells. Endocrinology 147, 4339-4350.

Guennoun, R., Benmessahel, Y., Delespierre, B., Gouezou, M., Rajkowski, K.M., Baulieu, E.E., Schumacher, M., 2001. Progesterone stimulates Krox-20 gene expression in Schwann cells. Brain Research Molecular Brain Research 90, 75-82.

Guerra-Araiza, C., Amorim, M.A., Camacho-Arroyo, I., Garcia-Segura, L.M., 2007 Effects of progesterone and its reduced metabolites, dihydroprogesterone and tetrahydroprogesterone, on the expression and phosphorylation of glycogen synthase kinase- 3 and the microtubule-associated protein tau in the rat cerebellum. Developmental Neurobiology 67, 510-520.

Guerra-Araiza, C., Amorim, M.A., Pinto-Almazan, R., Gonzalez-Arenas, A., Campos, M.G., Garcia-Segura, L.M., 2009. Regulation of the phosphoinositide-3 kinase and mitogen-activated protein kinase signaling pathways by progesterone and its reduced metabolites in the rat brain. Journal of Neuroscience Research 87, 470-481.

Guerra-Araiza, C., Villamar-Cruz, O., Gonzalez-Arenas, A., Chavira, R., CamachoArroyo, I., 2003. Changes in progesterone receptor isoforms content in the rat brain during the oestrous cycle and after oestradiol and progesterone treatments. Journal of Neuroendocrinology 15, 984-990.

He, J., Evans, C.O., Hoffman, S.W., Oyesiku, N.M., Stein, D.G., 2004. Progesterone and allopregnanolone reduce inflammatory cytokines after traumatic brain injury Experimental Neurology 189, 404-412. 
Holmqvist, P., Wallberg, M., Hammar, M., Landtblom, A.M., Brynhildsen, J., 2006. Symptoms of multiple sclerosis in women in relation to sex steroid exposure. Maturitas 54, 149-153.

Ibanez, C., Shields, S.A., El-Etr, M., Baulieu, E.E., Schumacher, M., Franklin, R.J., 2004 Systemic progesterone administration results in a partial reversal of the ageassociated decline in CNS remyelination following toxin-induced demyelination in male rats. Neuropathology and Applied Neurobiology 30, 80-89.

Ibanez, C., Shields, S.A., El-Etr, M., Leonelli, E., Magnaghi, V., Li, W.W., Sim, F.J., Baulieu, E.E., Melcangi, R.C., Schumacher, M., Franklin, R.J., 2003. Steroids and the reversal of age-associated changes in myelination and remyelination. Progress in Neurobiology 71, 49-56.

Irwig, M.S., 2012a. Depressive symptoms and suicidal thoughts among former users of finasteride with persistent sexual side effects. Journal of Clinical Psychiatry 73, 1220-1223

Irwig, M.S., 2012b. Persistent sexual side effects of finasteride: could they be permanent? Journal of Sexual Medicine 9, 2927-2932.

Ishrat, T., Sayeed, I., Atif, F., Hua, F., Stein, D.G.C.P., 2010. Progesterone and allopregnanolone attenuate blood-brain barrier dysfunction following permanen focal ischemia by regulating the expression of matrix metalloproteinases. Experimental Neurology 226, 183-190.

Jacobson, A.M., Samson, J.A., Weinger, K., Ryan, C.M., 2002. Diabetes, the brain, and behavior: is there a biological mechanism underlying the association between diabetes and depression? International Review of Neurobiology 51, 455-479.

Jiang, C., Cui, K., Wang, J., He, Y., 2011. Microglia and cyclooxygenase-2: possible therapeutic targets of progesterone for stroke. International Immunopharmacology 11, 1925-1931.

Jo, D.H., Abdallah, M.A., Young, J., Baulieu, E.E., Robel, P., 1989. Pregnenolone, dehydroepiandrosterone, and their sulfate and fatty acid esters in the rat brain. Steroids 54, 287-297.

Joseph, E.K., Levine, J.D., 2003. Sexual dimorphism in the contribution of protein kinase $C$ isoforms to nociception in the streptozotocin diabetic rat. Neuroscience $120,907-913$

Jung-Testas, I., Schumacher, M., Robel, P., Baulieu, E.E., 1996a. Demonstration of progesterone receptors in rat Schwann cells. The Journal of Steroid Biochemis try and Molecular Biology 58, 77-82.

Jung-Testas, I., Schumacher, M., Robel, P., Baulieu, E.E., 1996b. The neurosteroid progesterone increases the expression of myelin proteins (MBP and CNPase) in rat oligodendrocytes in primary culture. Cellular and Molecular Neurobiology 16, 439-443.

Kaur, P., Jodhka, P.K., Underwood, W.A., Bowles, C.A., de Fiebre, N.C., de Fiebre, C.M. Singh, M., 2007. Progesterone increases brain-derived neuroptrophic factor expression and protects against glutamate toxicity in a mitogen-activated protein kinase- and phosphoinositide-3 kinase-dependent manner in cerebral cortical explants. Journal of Neuroscience Research 85, 2441-2449.

Kaye, W., 2008. Neurobiology of anorexia and bulimia nervosa. Physiology \& Behavior 94, 121-135

Kim, H.J., Ha, M., Park, C.H., Park, S.J., Youn, S.M., Kang, S.S., Cho, G.J., Choi, W.S., 2003. StAR and steroidogenic enzyme transcriptional regulation in the rat brain: effects of acute alcohol administration. Brain Research Molecular Brain Research $115,39-49$

Kiziltan, M.E., Benbir, G., 2008. Clinical and electrophysiological differences in male and female patients with diabetic foot. Diabetes Research and Clinical Practice 79, e17-e18

Kiziltan, M.E., Gunduz, A., Kiziltan, G., Akalin, M.A., Uzun, N., 2007. Periphera neuropathy in patients with diabetic foot ulcers: clinical and nerve conduction study. Journal of Neurological Sciences 258, 75-79.

Kodl, C.T., Seaquist, E.R., 2008. Cognitive dysfunction and diabetes mellitus. Endocrine Reviews 29, 494-511.

Koenig, H.L., Schumacher, M., Ferzaz, B., Thi, A.N., Ressouches, A., Guennoun, R., Jung-Testas, I., Robel, P., Akwa, Y., Baulieu, E.E., 1995. Progesterone synthesis and myelin formation by Schwann cells. Science 268, 1500-1503.

Labombarda, F., Gonzalez, S., Gonzalez Deniselle, M.C., Garay, L., Guennoun, R., Schumacher, M., De Nicola, A.F., 2006a. Progesterone increases the expression of myelin basic protein and the number of cells showing NG2 immunostaining in the lesioned spinal cord. Journal of Neurotrauma 23, 181-192.

Labombarda, F., Gonzalez, S.L., Lima, A., Roig, P., Guennoun, R., Schumacher, M., de Nicola, A.F., 2009. Effects of progesterone on oligodendrocyte progenitors oligodendrocyte transcription factors, and myelin proteins following spina cord injury. Glia 57, 884-897.

Labombarda, F., Lima, G.S.A., Roig, P., Guennoun, R., Schumacher, M., De Nicola, A.F., 2011. Progesterone attenuates astro- and microgliosis and enhances oligodendrocyte differentiation following spinal cord injury. Experimental Neurology $231,135-146$.

Labombarda, F., Meffre, D., Delespierre, B., Krivokapic-Blondiaux, S., Chastre, A., Thomas, P., Pang, Y., Lydon, J.P., Gonzalez, S.L., De Nicola, A.F., Schumacher, M. Guennoun, R., 2010. Membrane progesterone receptors localization in the mouse spinal cord. Neuroscience 166, 94-106.

Labombarda, F., Pianos, A., Liere, P., Eychenne, B., Gonzalez, S., Cambourg, A., De Nicola, A.F., Schumacher, M., Guennoun, R., 2006b. Injury elicited increase in spinal cord neurosteroid content analyzed by gas chromatography mass spectrometry. Endocrinology 147, 1847-1859.

Lambert, J.J., Belelli, D., Peden, D.R., Vardy, A.W., Peters, J.A., 2003. Neurosteroid modulation of GABAA receptors. Progress in Neurobiology 71, 67-80.

Lanctot, K.L., Herrmann, N., Rothenburg, L., Eryavec, G., 2007. Behavioral correlates of GABAergic disruption in Alzheimer's disease. International Psychogeriatrics $19,151-158$
Lavaque, E., Sierra, A., Azcoitia, I., Garcia-Segura, L.M., 2006. Steroidogenic acute regulatory protein in the brain. Neuroscience 138, 741-747.

Lee, M., Schwab, C., McGeer, P.L., 2011. Astrocytes are GABAergic cells that modulate microglial activity. Glia 59, 152-165.

Leonelli, E., Bianchi, R., Cavaletti, G., Caruso, D., Crippa, D., Garcia-Segura, L.M. Lauria, G., Magnaghi, V., Roglio, I., Melcangi, R.C., 2007. Progesterone and its derivatives are neuroprotective agents in experimental diabetic neuropathy: a multimodal analysis. Neuroscience 144, 1293-1304.

Luchetti, S., Bossers, K., Frajese, G.V., Swaab, D.F., 2010. Neurosteroid biosynthetic pathway changes in substantia nigra and caudate nucleus in Parkinson's disease. Brain Pathology 20, 945-951.

Luchetti, S., Bossers, K., Van de Bilt, S., Agrapart, V., Morales, R.R., Frajese, G.V., Swaab, D.F., 2011a. Neurosteroid biosynthetic pathways changes in prefrontal cortex in Alzheimer's disease. Neurobiology of Aging 32, 1964-1976.

Luchetti, S., Huitinga, I., Swaab, D.F., 2011b. Neurosteroid and GABA-A receptor alterations in Alzheimer's disease, Parkinson's disease and multiple sclerosis. Neuroscience 191, 6-21.

Luquin, S., Naftolin, F., Garcia-Segura, L.M., 1993. Natural fluctuation and gonadal hormone regulation of astrocyte immunoreactivity in dentate gyrus. Journal of Neurobiology 24, 913-924.

Maccio, D.R., Calfa, G., Volosin, M., Roth, G.A., 2004. Serum testosterone and corticosterone levels in acute experimental autoimmune encephalomyelitis (EAE) in male Wistar rats. Neuro Endocrinology Letters 25, 196-200.

Magnaghi, V., Ballabio, M., Cavarretta, I.T., Froestl, W., Lambert, J.J., Zucchi, I., Melcangi, R.C., 2004. GABAB receptors in Schwann cells influence proliferation and myelin protein expression. European Journal of Neuroscience 19, $2641-$ 2649

Magnaghi, V., Ballabio, M., Roglio, I., Melcangi, R.C., 2007. Progesterone derivatives increase expression of Krox-20 and Sox-10 in rat Schwann cells. Journal of Molecular Neuroscience 31, 149-157.

Magnaghi, V., Cavarretta, I., Galbiati, M., Martini, L., Melcangi, R.C., 2001. Neuroactive steroids and peripheral myelin proteins. Brain Research Brain Research Reviews 37, 360-371.

Magnaghi, V., Cavarretta, I., Zucchi, I., Susani, L., Rupprecht, R., Hermann, B., Martini, L., Melcangi, R.C., 1999. Po gene expression is modulated by androgens in the sciatic nerve of adult male rats. Brain Research Molecular Brain Research 70, 36-44.

Magnaghi, V., Parducz, A., Frasca, A., Ballabio, M., Procacci, P., Racagni, G., Bonanno, G., Fumagalli, F., 2010. GABA synthesis in Schwann cells is induced by the neuroactive steroid allopregnanolone. Journal of Neurochemistry 112, 980-990.

Magnaghi, V., Veiga, S., Ballabio, M., Gonzalez, L.C., Garcia-Segura, L.M., Melcangi, R.C., 2006. Sex-dimorphic effects of progesterone and its reduced metabolites on gene expression of myelin proteins by rat Schwann cells. Journal of the Peripheral Nervous System 11, 111-118.

Majewska, M.D., Harrison, N.L., Schwartz, R.D., Barker, J.L., Paul, S.M., 1986. Steroid hormone metabolites are barbiturate-like modulators of the GABA receptor. Science 232, 1004-1007

Mani, S.K., Oyola, M.G., 2012. Progesterone signaling mechanisms in brain and behavior. Frontiers in Endocrinology (Lausanne) 3, 7

Marcus, S.M., Kerber, K.B., Rush, A.J., Wisniewski, S.R., Nierenberg, A., Balasubramani, G.K., Ritz, L., Kornstein, S., Young, E.A., Trivedi, M.H., 2008. Sex differences in depression symptoms in treatment-seeking adults: confirmatory analyses from the Sequenced Treatment Alternatives to Relieve Depression study. Comprehensive Psychiatry 49, 238-246.

Marx, C.E., Trost, W.T., Shampine, L.J., Stevens, R.D., Hulette, C.M., Steffens, D.C. Ervin, J.F., Butterfield, M.I., Blazer, D.G., Massing, M.W., Lieberman, J.A., 2006. The neurosteroid allopregnanolone is reduced in prefrontal cortex in Alzheimer's disease. Biological Psychiatry 60, 1287-1294.

McCall, A.L., 2002. Diabetes mellitus and the central nervous system. International Review of Neurobiology 51, 415-453.

McEwen, B.S., Woolley, C.S., 1994. Estradiol and progesterone regulate neuronal structure and synaptic connectivity in adult as well as developing brain. Experimental Gerontology 29, 431-436.

Meffre, D., Labombarda, F., Delespierre, B., Chastre, A., De Nicola, A.F., Stein, D.G., Schumacher, M., Guennoun, R., 2013. Distribution of membrane progesterone receptor alpha in the male mouse and rat brain and its regulation after traumatic brain injury. Neuroscience 231, 111-124.

Meffre, D., Pianos, A., Liere, P., Eychenne, B., Cambourg, A., Schumacher, M., Stein, D.G., Guennoun, R., 2007. Steroid profiling in brain and plasma of male and pseudopregnant female rats after traumatic brain injury: analysis by gas chromatography/mass spectrometry. Endocrinology 148, 2505-2517.

Melcangi, R.C., Azcoitia, I., Ballabio, M., Cavarretta, I., Gonzalez, L.C., Leonelli, E., Magnaghi, V., Veiga, S., Garcia-Segura, L.M., 2003a. Neuroactive steroids influence peripheral myelination: a promising opportunity for preventing or treating age-dependent dysfunctions of peripheral nerves. Progress in Neurobiology 71, 57-66.

Melcangi, R.C., Caruso, D., Levandis, G., Abbiati, F., Armentero, M.T., Blandini, F., 2012. Modifications of neuroactive steroid levels in an experimental model of nigrostriatal degeneration: potential relevance to the pathophysiology of Parkinson's Disease. Journal of Molecular Neuroscience 46, 177-183.

Melcangi, R.C., Cavarretta, I.T., Ballabio, M., Leonelli, E., Schenone, A., Azcoitia, I., Miguel Garcia-Segura, L., Magnaghi, V., 2005. Peripheral nerves: a target for the action of neuroactive steroids. Brain Research Brain Research Reviews 48, 328 338.

Melcangi, R.C., Garcia-Segura, L.M., 2010. Sex-specific therapeutic strategies based on neuroactive steroids: in search for innovative tools for neuroprotection. Hormones and Behavior 57, 2-11. 
Melcangi, R.C., Garcia-Segura, L.M., Mensah-Nyagan, A.G., 2008. Neuroactive steroids: state of the art and new perspectives. Cellular and Molecular Life Sciences 65, 777-797.

Melcangi, R.C., Giatti, S., Pesaresi, M., Calabrese, D., Mitro, N., Caruso, D., GarciaSegura, L.M., 2011. Role of neuroactive steroids in the peripheral nervous system. Frontiers in Endocrinology (Lausanne) 2, 104.

Melcangi, R.C., Leonelli, E., Magnaghi, V., Gherardi, G., Nobbio, L., Schenone, A., 2003b. Mifepristone (RU 38486) influences expression of glycoprotein Po and morphological parameters at the level of rat sciatic nerve: in vivo observations. Experimental Neurology 184, 930-938.

Melcangi, R.C., Magnaghi, V., Cavarretta, I., Martini, L., Piva, F., 1998. Age-induced decrease of glycoprotein Po and myelin basic protein gene expression in the rat sciatic nerve Repair by steroid derivatives. Neuroscience 85, 569-578.

Melcangi, R.C., Magnaghi, V., Cavarretta, I., Zucchi, I., Bovolin, P., D’Urso, D., Martini, L., 1999. Progesterone derivatives are able to influence peripheral myelin protein 22 and P0 gene expression: possible mechanisms of action. Journal of Neuroscience Research 56, 349-357.

Melcangi, R.C., Magnaghi, V., Galbiati, M., Ghelarducci, B., Sebastiani, L., Martini, L., 2000a. The action of steroid hormones on peripheral myelin proteins: a possible new tool for the rebuilding of myelin? Journal of Neurocytology 29, 327-339.

Melcangi, R.C., Magnaghi, V., Galbiati, M., Martini, L., 2001. Glial cells: a target for steroid hormones. Progress in Brain Research 132, 31-40.

Melcangi, R.C., Magnaghi, V., Martini, L., 2000b. Aging in peripheral nerves: regulation of myelin protein genes by steroid hormones. Progress in Neurobiology 60, 291-308.

Mercier, G., Turque, N., Schumacher, M., 2001. Early activation of transcription factor expression in Schwann cells by progesterone. Brain Research Molecular Brain Research 97, 137-148.

Meyer, L., Patte-Mensah, C., Taleb, O., Mensah-Nyagan, A.G., 2010. Cellular and functional evidence for a protective action of neurosteroids against vincristine chemotherapy-induced painful neuropathy. Cellular and Molecular Life Sciences 67, 3017-3034.

Meyer, L., Patte-Mensah, C., Taleb, O., Mensah-Nyagan, A.G., 2011. Allopregnanolone prevents and suppresses oxaliplatin-evoked painful neuropathy: multiparametric assessment and direct evidence. Pain 152, 170-181.

Micevych, P., Sinchak, K., 2008. Synthesis and function of hypothalamic neuroprogesterone in reproduction. Endocrinology 149, 2739-2742.

Mitro, N., Cermenati, G., Giatti, S., Abbiati, F., Pesaresi, M., Calabrese, D., GarciaSegura, L.M., Caruso, D., Melcangi, R.C., 2012. LXR and TSPO as new therapeutic targets to increase the levels of neuroactive steroids in the central nervous system of diabetic animals. Neurochemistry International 60, 616-621.

Murphy, D.D., Segal, M., 2000. Progesterone prevents estradiol-induced dendritic spine formation in cultured hippocampal neurons. Neuroendocrinology 72 $133-143$.

Niemeier, J.P., Marwitz, J.H., Lesher, K., Walker, W.C., Bushnik, T., 2007. Gender differences in executive functions following traumatic brain injury. Neuropsychological Rehabilitation 17, 293-313.

Nilsen, J., Brinton, R.D., 2002. Impact of progestins on estradiol potentiation of the glutamate calcium response. Neuroreport 13, 825-830.

Noonan, C.W., Kathman, S.J., White, M.C., 2002. Prevalence estimates for MS in the United States and evidence of an increasing trend for women. Neurology 58 $136-138$.

Noorbakhsh, F., Ellestad, K.K., Maingat, F., Warren, K.G., Han, M.H., Steinman, L., Baker, G.B., Power, C., 2011. Impaired neurosteroid synthesis in multiple sclerosis. Brain 134, 2703-2721

Orton, S.M., Herrera, B.M., Yee, I.M., Valdar, W., Ramagopalan, S.V., Sadovnick, A.D., Ebers, G.C., 2006. Sex ratio of multiple sclerosis in Canada: a longitudinal study. Lancet Neurology 5, 932-936.

Ozacmak, V.H., Sayan, H., 2009. The effects of 17beta estradiol, 17alpha estradiol and progesterone on oxidative stress biomarkers in ovariectomized female rat brain subjected to global cerebral ischemia. Physiological Research 58, 909-912.

Pang, Y., Dong, J., Thomas, P., 2013. Characterization, neurosteroid binding and brain distribution of human membrane progesterone receptors delta and \{epsilon (mPRdelta and mPR\{epsilon\}) and mPRdelta involvement in neurosteroid inhibition of apoptosis. Endocrinology 154, 283-295.

Panzica, G.C., Melcangi, R.C., 2008. The endocrine nervous system: source and target for neuroactive steroids. Brain Research Reviews 57, 271-276.

Papadopoulos, V., Baraldi, M., Guilarte, T.R., Knudsen, T.B., Lacapere, J.J., Lindemann, P., Norenberg, M.D., Nutt, D., Weizman, A., Zhang, M.R., Gavish, M., 2006a. Translocator protein $(18 \mathrm{kDa})$ : new nomenclature for the peripheral-type benzodiazepine receptor based on its structure and molecular function. Trends in Pharmacological Sciences 27, 402-409.

Papadopoulos, V., Lecanu, L., Brown, R.C., Han, Z., Yao, Z.X., 2006b. Peripheral-type benzodiazepine receptor in neurosteroid biosynthesis, neuropathology and neurological disorders. Neuroscience 138, 749-756.

Pelletier, G., 2010. Steroidogenic enzymes in the brain: morphological aspects. Progress in Brain Research 181, 193-207.

Perego, C., Cairano, E.S., Ballabio, M., Magnaghi, V., 2011. Neurosteroid allopregnanolone regulates EAAC1-mediated glutamate uptake and triggers actin changes in Schwann cells. Journal of Cellular Physiology 227, 1740-1751.

Perez, J., Luquin, S., Naftolin, F., Garcia-Segura, L.M., 1993. The role of estradiol and progesterone in phased synaptic remodelling of the rat arcuate nucleus. Brain Research 608, 38-44.

Pesaresi, M., Giatti, S., Calabrese, D., Maschi, O., Caruso, D., Melcangi, R.C., 2010a. Dihydroprogesterone increases the gene expression of myelin basic protein in spinal cord of diabetic rats. Journal of Molecular Neuroscience 42, 135-139.
Pesaresi, M., Maschi, O., Giatti, S., Garcia-Segura, L.M., Caruso, D., Melcangi, R.C., 2010b. Sex differences in neuroactive steroid levels in the nervous system of diabetic and non-diabetic rats. Hormones and Behavior 57, 46-55.

Pettus, E.H., Wright, D.W., Stein, D.G., Hoffman, S.W., 2005. Progesterone treatment inhibits the inflammatory agents that accompany traumatic brain injury. Brain Research 1049, 112-119.

Priyadarshini, M., Kamal, M.A., Greig, N.H., Realef, M., Abuzenadah, A.M., Chaudhary, A.G., Damanhouri, G., 2012. Alzheimer's disease and type 2 diabetes: exploring the association to obesity and tyrosine hydroxylase. CNS Neurological Disorder Drug Targets 11, 482-489.

Reyna-Neyra, A., Camacho-Arroyo, I., Ferrera, P., Arias, C., 2002. Estradiol and progesterone modify microtubule associated protein 2 content in the rat hippocampus. Brain Research Bulletin 58, 607-612.

Rhodes, M.E., Frye, C.A., 2004. Progestins in the hippocampus of female rats have antiseizure effects in a pentylenetetrazole seizure model. Epilepsia 45, 1531 1538 .

Robel, P., Young, J., Corpechot, C., Mayo, W., Perche, F., Haug, M., Simon, H., Baulieu, E.E., 1995. Biosynthesis and assay of neurosteroids in rats and mice: functional correlates. The Journal of Steroid Biochemistry and Molecular Biology 53, 355360.

Robertson, C.L., Puskar, A., Hoffman, G.E., Murphy, A.Z., Saraswati, M., Fiskum, G., 2006. Physiologic progesterone reduces mitochondrial dysfunction and hippocampal cell loss after traumatic brain injury in female rats. Experimental Neurology 197, 235-243.

Rodriguez-Waitkus, P.M., Lafollette, A.J., Ng, B.K., Zhu, T.S., Conrad, H.E., Glaser, M., 2003. Steroid hormone signaling between Schwann cells and neurons regulates the rate of myelin synthesis. Annals of the New York Academy of Sciences 1007 340-348.

Roglio, I., Bianchi, R., Camozzi, F., Carozzi, V., Cervellini, I., Crippa, D., Lauria, G., Cavaletti, G., Melcangi, R.C., 2009. Docetaxel-induced peripheral neuropathy: protective effects of dihydroprogesterone and progesterone in an experimental model. Journal of the Peripheral Nervous System 14, 36-44.

Roglio, I., Bianchi, R., Giatti, S., Cavaletti, G., Caruso, D., Scurati, S., Crippa, D., GarciaSegura, L.M., Camozzi, F., Lauria, G., Melcangi, R.C., 2007. Testosterone derivatives are neuroprotective agents in experimental diabetic neuropathy. Cellular and Molecular Life Sciences 64, 1158-1168.

Roglio, I., Bianchi, R., Gotti, S., Scurati, S., Giatti, S., Pesaresi, M., Caruso, D., Panzica, G.C., Melcangi, R.C., 2008. Neuroprotective effects of dihydroprogesterone and progesterone in an experimental model of nerve crush injury. Neuroscience $155,673-685$

Roof, R.L., Duvdevani, R., Braswell, L., Stein, D.G., 1994. Progesterone facilitates cognitive recovery and reduces secondary neuronal loss caused by cortical contusion injury in male rats. Experimental Neurology 129, 64-69.

Roof, R.L., Duvdevani, R., Heyburn, J.W., Stein, D.G., 1996. Progesterone rapidly decreases brain edema: treatment delayed up to 24 hours is still effective. Experimental Neurology 138, 246-251.

Roof, R.L., Hall, E.D., 2000. Gender differences in acute CNS trauma and stroke: neuroprotective effects of estrogen and progesterone. Journal of Neurotrauma $17,367-388$

Roof, R.L., Hoffman, S.W., Stein, D.G., 1997. Progesterone protects against lipid peroxidation following traumatic brain injury in rats. Molecular and Chemical Neuropathology 31, 1-11.

Safarinejad, M.R., 2008. Evaluation of endocrine profile, hypothalamic-pituitarytestis axis and semen quality in multiple sclerosis. Journal of Neuroendocrinology 20,1368-1375.

Salonia, A., Lanzi, R., Scavini, M., Pontillo, M., Gatti, E., Petrella, G., Licata, G., Nappi, R.E., Bosi, E., Briganti, A., Rigatti, P., Montorsi, F., 2006. Sexual function and endocrine profile in fertile women with type 1 diabetes. Diabetes Care 29, 312316.

Sayeed, I., Guo, Q., Hoffman, S.W., Stein, D.G., 2006. Allopregnanolone, a progesterone metabolite, is more effective than progesterone in reducing cortical infarct volume after transient middle cerebral artery occlusion. Annals of Emergency Medicine 47, 381-389.

Sayeed, I., Parvez, S., Wali, B., Siemen, D., Stein, D.G., 2009. Direct inhibition of the mitochondrial permeability transition pore: a possible mechanism for better neuroprotective effects of allopregnanolone over progesterone. Brain Research 1263, 165-173.

Sayeed, I., Wali, B., Stein, D.G., 2007. Progesterone inhibits ischemic brain injury in a rat model of permanent middle cerebral artery occlusion. Restorative Neurology and Neuroscience 25, 151-159.

Schwendimann, R.N., Alekseeva, N., 2007. Gender issues in multiple sclerosis. International Review of Neurobiology 79, 377-392.

Skinner, D.C., Evans, N.P., Delaleu, B., Goodman, R.L., Bouchard, P., Caraty, A., 1998. The negative feedback actions of progesterone on gonadotropin-releasing hormone secretion are transduced by the classical progesterone receptor. Proceedings of National Academy of Sciences United States of America 95, 10978-10983.

Simonds, V.M., Whiffen, V.E., 2003. Are gender differences in depression explained by gender differences in co-morbid anxiety? Journal of Affective Disorders 77, 197-202.

Singh, C., Liu, L., Wang, J.M., Irwin, R.W., Yao, J., Chen, S., Henry, S., Thompson, R.F., Brinton, R.D., 2011. Allopregnanolone restores hippocampal-dependent learning and memory and neural progenitor survival in aging 3xTgAD and nonTg mice. Neurobiology of Aging 33, 1493-1506.

Singh, M., 2005. Mechanisms of progesterone-induced neuroprotection. Annals of the New York Academy of Sciences 1052, 145-151. 
Singh, M., Su, C., 2013a. Progesterone-induced neuroprotection: factors that may predict therapeutic efficacy. Brain Research, http://dx.doi.org/10.1016/ j.brainres.2013.01.027.

Singh, M., Su, C., 2013b. Progesterone, brain-derived neurotrophic factor and neuroprotection. Neuroscience 239, 84-91.

Steen, E., Terry, B.M., Rivera, E.J., Cannon, J.L., Neely, T.R., Tavares, R., Xu, X.J., Wands, J.R., de la Monte, S.M., 2005. Impaired insulin and insulin-like growth factor expression and signaling mechanisms in Alzheimer's disease-is this type 3 diabetes? Journal of Alzheimers Disease 7, 63-80.

Stein, D.G., 2011. Progesterone in the treatment of acute traumatic brain injury: a clinical perspective and update. Neuroscience 191, 101-106.

Su, C., Cunningham, R.L., Rybalchenko, N., Singh, M., 2012. Progesterone increase the release of brain-derived neurotrophic factor from glia via progesterone receptor membrane component 1 (Pgrmc1)-dependent ERK5 signaling. Endocrinology 153, 4389-4400.

Sugimoto, K., Murakawa, Y., Sima, A.A., 2000. Diabetic neuropathy-a continuing enigma. Diabetes/Metabolism Research and Reviews 16, 408-433.

Sun, C., Ou, X., Farley, J.M., Stockmeier, C., Bigler, S., Brinton, R.D., Wang, J.M., 2012. Allopregnanolone increases the number of dopaminergic neurons in substantia nigra of a triple transgenic mouse model of Alzheimer's disease. Current Alzheimers Research 9, 473-480.

Takeda, S., Sato, N., Rakugi, H., Morishita, R., 2011. Molecular mechanisms linking diabetes mellitus and Alzheimer disease: beta-amyloid peptide, insulin signaling, and neuronal function. Molecular Biosystems 7, 1822-1827.

Tanaka, M., Nakaya, S., Kumai, T., Watanabe, M., Matsumoto, N., Kobayashi, S., 2001. Impaired testicular function in rats with diet-induced hypercholesterolemia and or streptozotocin-induced diabetes mellitus. Endocrine Research 27, 109-117.

Thomas, A.J., Nockels, R.P., Pan, H.Q., Shaffrey, C.I., Chopp, M., 1999. Progesterone is neuroprotective after acute experimental spinal cord trauma in rats. Spine (Phila Pa 1976) 24, 2134-2138.

Thomas, P., Pang, Y., 2012. Membrane progesterone receptors: evidence for neuroprotective, neurosteroid signaling and neuroendocrine functions in neuronal cells. Neuroendocrinology 96, 162-171.

Tomassini, V., Onesti, E., Mainero, C., Giugni, E., Paolillo, A., Salvetti, M., Nicoletti, F. Pozzilli, C., 2005. Sex hormones modulate brain damage in multiple sclerosis: MRI evidence. Journal of Neurology, Neurosurgery, and Psychiatry 76, 272-275.

Tomassini, V., Pozzilli, C., 2006. Sex hormones: a role in the control of multiple sclerosis? Expert Opinion on Pharmacotherapy 7, 857-868.

Tsutsui, K., Ukena, K., Sakamoto, H., Okuyama, S., Haraguchi, S., 2011. Biosynthesis mode of action, and functional significance of neurosteroids in the purkinje cell. Frontiers in Endocrinology (Lausanne) 2, 61

Turkmen, S., Backstrom, T., Wahlstrom, G., Andreen, L., Johansson, I.M., 2011. Tolerance to allopregnanolone with focus on the GABA-A receptor. British Journal of Pharmacology 162, 311-327. van Dam, E.W., Dekker, J.M., Lentjes, E.G., Romijn, F.P., Smulders, Y.M., Post, W.J., Romijn, J.A., Krans, H.M., 2003. Steroids in adult men with type 1 diabetes: a tendency to hypogonadism. Diabetes Care 26, 1812-1818.

VanLandingham, J.W., Cekic, M., Cutler, S., Hoffman, S.W., Stein, D.G.C.P., 2007. Neurosteroids reduce inflammation after TBI through CD55 induction. Neuroscience Letters 425, 94-98.

Veiga, S., Leonelli, E., Beelke, M., Garcia-Segura, L.M., Melcangi, R.C., 2006. Neuroactive steroids prevent peripheral myelin alterations induced by diabetes. Neuroscience Letters 402, 150-153.

Vinik, A.I., Park, T.S., Stansberry, K.B., Pittenger, G.L., 2000. Diabetic neuropathies. Diabetologia 43, 957-973.

Vukusic, S., Confavreux, C., 2006. Pregnancy and multiple sclerosis: the children of PRIMS. Clinical Neurology and Neurosurgery 108, 266-270.

Vukusic, S., Hutchinson, M., Hours, M., Moreau, T., Cortinovis-Tourniaire, P., Adeleine, P., Confavreux, C., The Pregnancy In Multiple Sclerosis, G., 2004. Pregnancy and multiple sclerosis (the PRIMS study): clinical predictors of post-partum relapse. Brain 127, 1353-1360.

Wang, J.M., Liu, L., Irwin, R.W., Chen, S., Brinton, R.D., 2008. Regenerative potential of allopregnanolone. Brain Research Reviews 57, 398-409.

Wang, J.M., Singh, C., Liu, L., Irwin, R.W., Chen, S., Chung, E.J., Thompson, R.F., Brinton, R.D., 2010. Allopregnanolone reverses neurogenic and cognitive deficits in mouse model of Alzheimer's disease. Proceedings of National Academy of Sciences United States of America 107, 6498-6503.

Wang, M., 2011. Neurosteroids and GABA-A Receptor Function. Frontiers in Endocrinology (Lausanne) 2, 44.

Wang, M., He, Y., Eisenman, L.N., Fields, C., Zeng, C.M., Mathews, J., Benz, A., Fu, T., Zorumski, E., Steinbach, J.H., Covey, D.F., Zorumski, C.F., Mennerick, S., 2002. 3Beta-hydroxypregnane steroids are pregnenolone sulfate-like GABA(A) receptor antagonists. Journal of Neuroscience 22, 3366-3375.

Whittaker, M.T. Gibbs, T.T., Farb, D.H., 2008. Pregnenolone sulfate induces NMDA receptor dependent release of dopamine from synaptic terminals in the striatum. Journal of Neurochemistry 107, 510-521.

Wirth, M.M., 2011. Beyond the HPA axis: progesterone-derived neuroactive steroids in human stress and emotion. Frontiers in Endocrinology (Lausanne) $2,19$.

Woolley, C.S., McEwen, B.S., 1993. Roles of estradiol and progesterone in regulation of hippocampal dendritic spine density during the estrous cycle in the rat. Journal of Comparative Neurology 336, 293-306.

Yao, X.L., Liu, J., Lee, E., Ling, G.S., McCabe, J.T., 2005. Progesterone differentially regulates pro- and anti-apoptotic gene expression in cerebral cortex following traumatic brain injury in rats. Journal of Neurotrauma 22, 656-668.

Yu, W.H., 1989. Survival of motoneurons following axotomy is enhanced by lactation or by progesterone treatment. Brain Research 491, 379-382. 